\title{
Temporal analysis of the performance of an elevated concrete tank considering the corrosion of the steel reinforcement.
}

\author{
Nassima Miloudi, Karima Bouzelha, Hocine Hammoum \\ Department of civil engineering, Mouloud Mammeri University, 15000 Tiæi Ouzou, Algeria. \\ nassima.miloudi@ummto.dz,karima.bouzelha@ummto.dz. \\ hocine.bammoum@ummto.dz,,bttps://orcid.org/0000-0002-1481-6241
}

Younes Aoues

Laboratoire d'Optimisation et Fiabilité en Mécanique des Structures, INS A de Rouen, France. younes.aoues@insa-rouen.fr

\section{Ouali Amiri}

Institut de recherche en génie civil et mécanique IEG - GeM, Polytech Nantes, France. oualiamiri@univ-nantes.fr

\begin{abstract}
Reinforced concrete water storage tanks are civil engineering structures subject to very aggressive atmospheric conditions that expose them to harmful corrosion risk. This dangerous phenomenon caused by the penetration of chloride ions causes pitting corrosion and leads to the reduction of the section of the reinforcements and consequently to the loss of strength and the structure performance. In this study, we are interested in analyzing the performance of an elevated storage tank, taking into account the corrosion of the reinforcements subjected to tensile stress, by considering environments with different rates of aggressiveness. A method based on Housner's model is used to evaluate the tension stresses in the reinforced concrete (RC) pedestal (supporting system) of the tank, subjected to the seismic actions. A pitting corrosion model is developed in order to determine the evolution in time of the reinforcements section in different environments. Several parameters influencing corrosion are taken into account, such as concrete cover and the concentration of chlorides ions.
\end{abstract}

KEYWORDS. RC elevated tank; Pitting corrosion; Reinforcement; Performance; Seismic actions; Lifetime.

\section{OPEN ACCESS}

Citation: Miloudi, N., Bouzelha, K., Hammoum, H., Aoues, Y., Amiri, O., Temporal analysis of the performance of an elevated concrete tank considering the corrosion of the steel reinforcement, Frattura ed Integrità Strutturale, 56 (2021) 94-114.

Received: 16.01 .2021

Accepted: 26.02.2021

Published: 01.04.2021

Copyright: (C) 2021 This is an open access article under the terms of the CC-BY 4.0, which permits unrestricted use, distribution, and reproduction in any medium, provided the original author and source are credited. 


\section{INTRODUCTION}

W

hether one is interested in the management of existing structures or the design of new structures, one of the major issues is the control of their lifespan, while maintaining a guarantee of optimal response to performance requirements. These are conditioned by the response of the structures to physical and chemical attacks from the environment [1], as well as by the ability of the constituent materials to protect themselves against these attacks. The prediction of the lifetime of a structure has become a fundamental requirement, particularly for those of vital importance, such as RC storage tanks, classified as structures of great importance, from Class 1B according to Algerian Seismic code (RPA) [2]. They are considered to be extremely stressed structures, intended to storage water for distribution to subscribers. In order to ensure a sufficient hydraulic pressure in drinking water supply networks, tanks are preferably located on sites such as hilltops and mounds, exposing them to very harsh conditions of aggressiveness. These extreme conditions expose them to the corrosion risk of the reinforcements, thus reducing the performance of their resistant elements [3]. In addition, this type of structure is particularly vulnerable to the hydrodynamic effect under seismic action. The hydrodynamic behaviour of water storage tanks has been the subject of several researches in order to improve their design and their strength to high seismic loads. The first published work in this field was carried out by Hoskin and Jacobsen [4] who, based on the work of Westergaard [5] on rigid rectangular gravity dams, conducted theoretical and experimental studies to evaluate the hydrodynamic pressures developed in rectangular tanks subjected to seismic excitation. Subsequently, Housner's work $[6,7]$ made it possible to formulate the simplified analytical method, according to which the reservoirs are replaced by an equivalent system with two degrees of freedom, concentrating the mass of the structure at two points (impulsive and convective). This method, which is still used nowadays by practical engineers, has largely answered the problematic of the seismic response of liquid storage tanks. Later, in the 1970s, Epstein [8], based on Housner's model, developed formulas and dimensioning curves to estimate bending and overturning moments in rectangular and cylindrical tanks subjected to seismic action. Still based on Housner's model, Hammoum et al. [9] were interested in the analysis of circular and elevated RC reservoirs, and proposed a modelling of the hydrodynamic effect, taking into account the seismic action represented by a response spectrum given by RPA [2]. These authors show that the negligence of the hydrodynamic phenomenon would considerably underestimate the normal vertical tensile stresses acting in the RC pedestal. Indeed, contrary to what is stated in the RPA [2], the consideration of the hydrodynamic effect in the dimensioning calculations is necessary whatever their storage capacity and seismic zone. Aliche et al. [10] presented a probabilistic approach, based on the Monte Carlo simulation method, to develop fragility curves to represent the failure probability of RC elevated tanks at different levels of seismic acceleration and for different soil types.

However, reinforcement's corrosion is considered to be one of the main causes of deterioration of RC structures over time [11]. This corrosion does not develop as long as the concrete ensures physical or chemical protection to the reinforcements [12]. Indeed, the hydration of the cement produces a basic interstitial solution with a high pH (about 13) which gives permanent stability to the rust layer adhering to the reinforcements embedded in the concrete; which phenomenon is called passivation. Steel can be depassivated by two main mechanisms: the carbonation of concrete by carbon dioxide $\left(\mathrm{CO}_{2}\right)$ from the atmosphere or the penetration of chloride ions coming from sea water, sea spray or deicing salts [13]. Concrete carbonation corrosion affects large zones of reinforcement with a more or less uniform loss around the perimeter of the reinforcing bars, whereas pitting corrosion is localized on small areas and results in a substantial reduction in their cross section [14]. This study will focus on pitting corrosion because it is more dangerous than uniform corrosion. In the lifetime of a RC structure, we can distinguish two phases of corrosion: a corrosion initiation phase and a propagation phase. The duration of the initiation phase is determined by the speed of neutralisation of the cover concrete, or the speed of penetration of aggressive agents, such as chlorides [15]. When the chloride concentration in the steel bars reaches the threshold concentration, the propagation phase begins, the steel corrodes, its section decreases causing the ruin of the structure [12]. Tutti's diagram (Fig.1) summarizes in two stages (initiation, propagation) the corrosion mechanism that leads to the deterioration of structures [16].

The initiation time is defined by Portuguese researchers group [18] for uniform corrosion and by Duracrate [15] for pitting corrosion. In order to estimate the loss of section induced by corrosion in concrete, several models have been proposed to express the uniform corrosion current (Duracrete, Li and Lawanwisut, Gonzales et al., Gonzales et al., Tuutti) and the pitting corrosion current (Liu and Weyers, Vu and Stewart, Vu et al., Gonzales et al., Tuutti) [19]. The choice of the model depends on the input parameters which must be modelled so that the results are realistic. Few researches have been done on estimating the durability and performance of RC storage tanks considering the reinforcement corrosion. We can cite the work of Bouzelha et al. [20] treating the analysis of the performance of a storage 
tank posed on the ground, taking into account the corrosion phenomenon of the reinforcements and considering environments with different rates of aggressiveness.

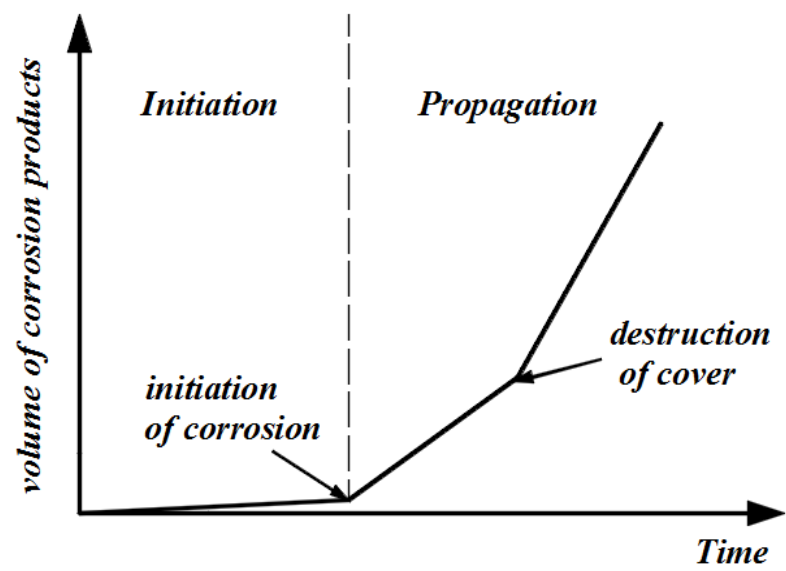

Figure 1: Schematic degradation of steel reinforcement over time [17].

The research work presented in this paper is a continuation of the work carried out by Bouzelha et al. [20]. The objective is the analysis of the vertical tensile stresses of the pedestal of an elevated concrete tank, under seismic action, taking into account corrosion by penetration of chloride ions, inducing pitting corrosion. For the evaluation of these tensile stresses, the Housner's model [9] is thus used to simulate the hydrodynamic effect, which will be briefly presented in section 2 . In section 3, we study the evolution of pitting corrosion rates in tensile stress steels, using the model of Liu and Weyers [21], which is quite entire because it takes into account several parameters of environmental influence. As for the initiation time, it is evaluated with the model proposed by Duracrete [15]. In section 4, we present a practical application, where the lifetime of the elevated tank is estimated by considering environments with different aggressiveness, as well as different seismic zones. The influence of different parameters on corrosion is analysed, such as cover concrete, chlorides concentration, cement content and environmental parameters. Relevant conclusions and recommendations are thus provided in the final section.

\section{DETERMINISTIC APPROACH FOR THE EVALUATION OF VERTICAL TENSILE STRESSES IN THE SUPPORT}

$\mathrm{H}$

ousner's model decomposes the action of the water contained in the storage tank into two actions: an impulsive action causing impulsive efforts and convective action causing convective efforts [22]. Thus, the modelling of the entire reservoir is represented by its mechanical equivalent and its mathematical model with two degrees of freedom, as shown in Fig. 2.

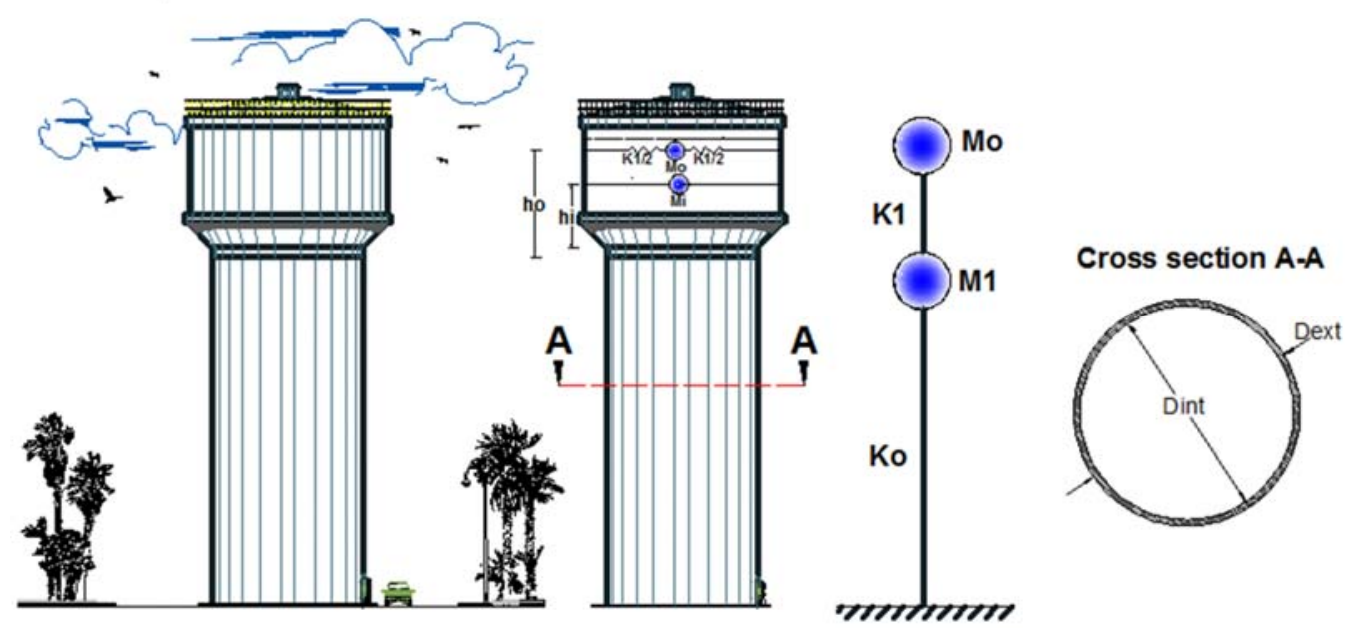

Figure 2: Elevated tank - equivalent mechanical and mathematical models. 
In the adopted mathematical model, the mass $\mathrm{M}_{0}$ representing the part of the water oscillating, is connected to the structure by a rod of the same stiffness $\mathrm{K}_{1}$ forming a direct coupling with $\mathrm{M}_{1}$.

$$
\mathrm{F}_{\mathrm{ki}}=\frac{\mathrm{S}_{\mathrm{ai}}}{\mathrm{g}} \cdot \gamma_{\mathrm{i}} \cdot \mathrm{M}_{\mathrm{k}} \cdot \mathrm{a}_{\mathrm{ki}}
$$

$\mathrm{S}_{\mathrm{ai}}$ : Ground Acceleration in "i" mode;

$\mathrm{M}_{\mathrm{k}}$ : Level "k" mass;

$a_{\mathrm{k} i}:$ Mass amplitude "k" in mode "i";

$\gamma_{i}$ : Modal distribution coefficient (mode i), given by the following formula:

$$
\gamma_{i}=\frac{\sum_{k=1}^{2} \mathrm{M}_{\mathrm{k}} \cdot \mathrm{a}_{\mathrm{ki}}}{\sum_{\mathrm{k}=1}^{2} \mathrm{M}_{\mathrm{k}} \cdot \mathrm{a}_{\mathrm{ki}}^{2}}
$$

The resultant of the calculated seismic force applied to each mass $\mathrm{M}_{\mathrm{k}}$ is given by:

$$
\mathrm{F}_{\mathrm{k}}=\sqrt{\sum_{\mathrm{i}=1}^{2} \mathrm{~F}_{\mathrm{ki}}^{2}}
$$

The pedestal is subjected to a normal vertical stress noted $\mathrm{N}$, representing the weight of the empty storage tank augmented by the weight of the water it contains as well as the weight of the support tower, and to a bending moment noted $\mathrm{M}$, due to lateral seismic forces $\left(\mathrm{F}_{0}\right.$ and $\left.\mathrm{F}_{1}\right)$. The pedestal is then stressed in compound bending $(\mathrm{M}, \mathrm{N})$. Normal compressive and tensile stresses are developed on the extreme fibres of the pedestal. In this study, we are interested in the tensile stresses; they are estimated using the following relation:

$$
\sigma=\frac{\mathrm{N}}{\Omega}-\frac{\mathrm{M}}{\mathrm{I}} \mathrm{V}
$$

$\mathrm{v}$ represents the distance of the most tense fibre of the pedestal from an axis passing through the gravity centre of the tank.

The section of the pedestal noted $\Omega$ has the shape of a ring, and its horizontal section is given by:

$$
\Omega=\frac{\pi}{4}\left(\mathrm{D}_{\mathrm{ext}}^{2}-\mathrm{D}_{\mathrm{int}}^{2}\right)
$$

where, $D_{\text {int }}$ and $D_{\text {ext }}$ refer respectively to the internal and external diameter of the pedestal.

The moment of inertia of the pedestal, with respect of an axis passing through the gravity centre of the tank, is given by:

$$
\mathrm{I}=\frac{\pi}{64}\left(\mathrm{D}_{\mathrm{ext}}^{4}-\mathrm{D}_{\mathrm{int}}^{4}\right)
$$

The vertical tensile stress at the base of a fully tensioned linear band of the support, of thickness $e_{s}$, is expressed at the serviceability limit state (SLS) by the following relationship:

$$
\mathrm{T}_{\mathrm{s}}=\sigma \cdot \mathrm{e}_{\mathrm{s}}
$$

The necessary reinforcements section is thus deduced from the serviceability limit state by the following relation:

$$
\mathrm{A}_{\text {nec }} \geq \frac{\mathrm{T}_{\mathrm{s}}}{\overline{\sigma_{\mathrm{st}}}}
$$


$\overline{\sigma_{\text {st }}}$, is the tensile stress limit of steels, considering very detrimental cracking according to Fascicule 74 [23], is defined as follows:

$$
\overline{\sigma_{\mathrm{st}}}=0.8 \min \left\{\frac{2}{3} \mathrm{f}_{\mathrm{e}} ; \max \left(\frac{\mathrm{f}_{\mathrm{e}}}{2} ; 90 \sqrt{\eta \mathrm{f}_{\mathrm{tj}}}\right)\right\}
$$

where $\mathrm{f}_{\mathrm{e}}$ and $\mathrm{f}_{\mathrm{t} 28}$ respectively denote the elastic limit of steels and the tensile strength of concrete at 28 days. In practice, the reinforcements section initially adopted $(a t=0)$ for a unit band ( 1 linear meter) is given by:

$$
A_{s}(0)=n_{b} \frac{\pi d_{0}^{2}}{4}
$$

where:

$n_{b}:$ is the number of bars adopted on a unit band of the pedestal.

$d_{0}:$ is the initial diameter of a steel bar.

\section{MECHANICAL MODEL OF REINFORCEMENTS CORROSION}

$\mathrm{I}$

$\mathrm{n}$ this study, we put forward the hypothesis that the state of corrosion progress at a given time $\mathrm{t}$, is uniform on the bars of the same unit band, since they are subjected to the same aggression from the environment. It then comes that the section of longitudinal reinforcements tended at time $t$ which we denote $A_{s}(t)$ of a unit band at the base of the pedestal, is expressed as follows:

$$
A_{s}(t)=n_{b} A_{r}(t)
$$

$A_{r}(t)$ is the residual section of a steel bar at time t, given by the Eqn. (12), as a function of the initial bar diameter $\mathrm{d}_{0}$ and the pitting depth $\mathrm{p}(\mathrm{t})[14]$, as shown in Fig. 3 :

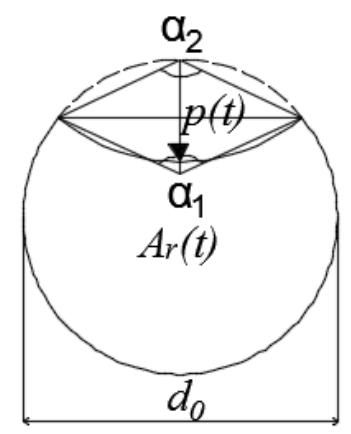

Figure 3: Pit Configuration [24].

$$
A_{r}(t)=\left\{\begin{array}{llr}
\frac{\pi d_{0}^{2}}{4}-A_{1}-A_{2} & \text { if } & p(t) \leq \frac{d_{0}}{\sqrt{2}} \\
A_{1}-A_{2} & \text { if } & \frac{d_{0}}{\sqrt{2}}<p(t) \leq d_{0} \\
0 & \text { if } & p(t)>d_{0}
\end{array}\right.
$$


where:

$$
\begin{aligned}
& A_{1}=\frac{1}{2}\left[\alpha_{1}\left(\frac{d_{0}}{2}\right)^{2}-a\left|\frac{d_{0}}{2}-\frac{p(t)^{2}}{d_{0}}\right|\right] \\
& \mathrm{A}_{2}=\frac{1}{2}\left[\alpha_{2} \mathrm{p}(\mathrm{t})^{2}-a \frac{\mathrm{p}(\mathrm{t})^{2}}{\mathrm{~d}_{0}}\right] \\
& a=2 \mathrm{p}(\mathrm{t}) \sqrt{1-\left(\frac{\mathrm{p}(\mathrm{t})}{\mathrm{d}_{0}}\right)^{2}} \\
& \alpha_{1}=2 \arcsin \left(\frac{a}{d_{0}}\right) \\
& \alpha_{2}=2 \arcsin \left(\frac{\mathrm{a}}{2 \mathrm{p}(\mathrm{t})}\right)
\end{aligned}
$$

Val et al. [24] suppose a spherical shape of the pitting (Fig. 3) and define its maximum depth by the following relation:

$$
\mathrm{p}(\mathrm{t})=0.0116 \alpha \int_{\mathrm{t}_{\text {ini }}}^{\mathrm{t}} \mathrm{i}_{\text {corr }} \mathrm{dt}
$$

where $\alpha$ is the pitting factor that takes into account the non-uniform corrosion along the reinforcement bars.

The corrosion current density $i_{\text {corr }}$ is estimated as proposed by Liu and Weyers model [21]:

$$
\mathrm{i}_{\text {cor }}=\frac{1}{1.08} \exp \left[8.37+0.618 \ln \left(1.69 \mathrm{C}_{\mathrm{s}}\right)-\frac{3034}{\mathrm{~T}}-0.000105 \mathrm{R}_{\mathrm{c}}+\frac{2.32}{\mathrm{t}_{\text {ini }}^{0.215}}\right]
$$

This model takes into account several parameters, such as the concentration of chlorides on the surface of the steels $\left(C_{s}\right)$, the ambient temperature $(T)$, the resistivity of concrete $\left(R_{c}\right)$ and the corrosion initiation time $\left(t_{\text {ini }}\right)$. The latter is obtained from the second law of Fick, which express the diffusion of chloride in concrete using the partial differential equation in the following form:

$$
\frac{\partial \mathrm{C}(\mathrm{x}, \mathrm{t})}{\partial \mathrm{t}}=\mathrm{D}_{\mathrm{cl}} \frac{\partial^{2} \mathrm{C}(\mathrm{x}, \mathrm{t})}{\partial \mathrm{x}^{2}}
$$

$\mathrm{C}(\mathrm{x}, \mathrm{t})$ is the concentration of free chlorides inside the concrete at carbonation depth $(\mathrm{x})$ and time $(\mathrm{t})$, and $\mathrm{D}_{\mathrm{cl}}$ is the effective chloride diffusion coefficient.

The resolution of Fick's Second Law is carried out, taking into account the following hypotheses [15]:

- Isotropic, saturated and semi-infinite domain;

- diffusion coefficient independent of time and space;

- Chloride concentration at the surface is constant and chloride concentration in the concrete at the initial time $(\mathrm{t}=0)$ is zero.

Thus, the concentration of chlorides is given by:

$$
C(x, t)=C_{s}\left[1-\operatorname{erf}\left(\frac{x}{2 \sqrt{D_{c l} t}}\right)\right]
$$


Erf(.) is the error function defined by McGee [25]:

$$
\operatorname{erf}(\mathrm{x})=\frac{2}{\sqrt{\pi}} \int_{0}^{\mathrm{x}} \mathrm{e}^{-\mathrm{t}^{2}} \mathrm{dt}=\frac{2}{\sqrt{\pi}}\left(\frac{1 \cdot \mathrm{x}}{0 ! .1}-\frac{1 \cdot \mathrm{x}^{3}}{1 ! \cdot 3}+\frac{1 \cdot \mathrm{x}^{5}}{2 ! .5}-\frac{1 \cdot \mathrm{x}^{7}}{3 ! .7}+\ldots\right)
$$

The diffusion coefficient of chlorides $\mathrm{D}_{\mathrm{cl}}$ depends mainly on the composition of the concrete. It is influenced by the mixing proportions (water, aggregate and cement), by the environment (relative humidity and temperature) and is variable as a function of time, as given by Duracrete [15]:

$$
D_{c l}(t)=D_{c l}\left(t_{0}\right)\left(\frac{t_{0}}{t_{\text {ini }}}\right)^{n}=k_{e} \cdot k_{t} \cdot k_{c} \cdot D_{0} \cdot\left(\frac{t_{0}}{t_{\text {ini }}}\right)^{n}
$$

where:

$\mathrm{D}_{0}:$ Diffusion coefficient effected at the reference time $\mathrm{t}_{0}\left(\mathrm{~m}^{2} / \mathrm{s}\right) ;$

$\mathrm{k}_{\mathrm{e}}$ : Factor taking into account the characteristics of the environment ;

$\mathrm{k}_{\mathrm{t}}$ : Factor used to determine $\mathrm{D}_{0}$;

$\mathrm{k}_{\mathrm{c}}$ : Factor taking into account the cure time ;

$\mathrm{t}_{0}$ : Time for which $\mathrm{D}_{0}$ was measured (days);

$\mathrm{n}$ : Aging factor.

Corrosion is initiated when the concentration of chloride ions $\mathrm{C}(\mathrm{x}, \mathrm{t})$ reaches the threshold limit or critical concentration $\mathrm{C}_{\mathrm{cr}}$, and the carbonation depth $(\mathrm{x})$ reaches the concrete cover (e). This combined effect of chlorides and carbonation leads to a depassivation of steel reinforcement. The result is:

$$
\mathrm{t}_{\mathrm{ini}}=\left(\left(\frac{\mathrm{e}^{2}}{4 \mathrm{k}_{\mathrm{e}} \mathrm{k}_{\mathrm{t}} \mathrm{k}_{\mathrm{c}} \mathrm{D}_{0}\left(\mathrm{t}_{0}\right)^{\mathrm{n}}}\right)\left[\operatorname{erf}^{-1}\left(1-\frac{\mathrm{C}_{\mathrm{cr}}}{\mathrm{C}_{\mathrm{s}}}\right)\right]^{-2}\right)^{\frac{1}{1-\mathrm{n}}}
$$

Note that the diffusion coefficient of chlorides $D_{c l}$ is expressed mainly in $10^{-12} \mathrm{~m}^{2} / \mathrm{s}$ or more rarely in [ $\mathrm{mm}^{2} / \mathrm{year}$. The units should be consistent with those of depth $\mathrm{x}$ and time $\mathrm{t}$.

\section{Practical APPlication}

7 he practical application presented here concerns the analysis of an elevated water storage tank with a capacity of $200 \mathrm{~m}^{3}$ posed on a pedestal (tower support) (Fig. 4). The geometric characteristics of the tank are shown in Tab. 1.
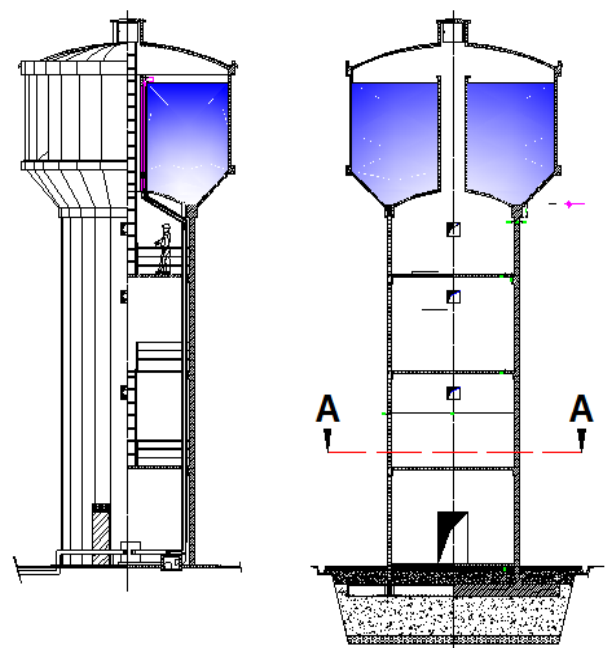

\section{Cross section A-A}

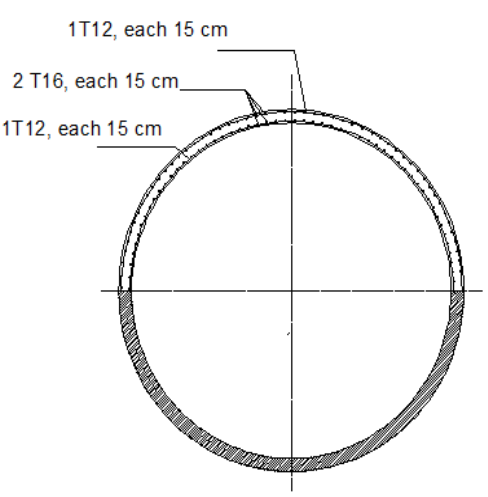

Figure 4: The studied elevated tank with the adopted reinforcement of the pedestal in a very high seismicity zone. 


\begin{tabular}{|c|c|}
\hline Internal diameter of the tank $[\mathrm{m}]$ & 8.20 \\
\hline Average water height in the tank [m] & 4.95 \\
\hline Height of the pedestal [m] & 14.50 \\
\hline Internal diameter of the tower support [m] & 5.00 \\
\hline External diameter of the tower support [m] & 5.40 \\
\hline Tower support thickness [m] & 0.20 \\
\hline Real tank volume $\left[\mathrm{m}^{3}\right]$ & 200.50 \\
\hline Concrete cover $[\mathrm{mm}]$ & 40 \\
\hline
\end{tabular}

Table 1: Geometrical characteristics of the tank [9].

\section{Evaluation of the vertical reinforcements section of the pedestal}

The tensioned reinforcement sections are evaluated using the method outlined in Section 2 for the unit band of the concrete pedestal for various seismic zones defined by RPA [2]. The necessary reinforcements sections obtained from the stress analysis as well as those adopted are shown in Tab. 2.

\begin{tabular}{lcccc}
\hline Seismic zones & $\begin{array}{c}\text { Zone I } \\
\text { Low seismicity }\end{array}$ & $\begin{array}{c}\text { Zone IIa } \\
\text { Average } \\
\text { seismicity }\end{array}$ & $\begin{array}{c}\text { Zone IIb } \\
\text { High } \\
\text { seismicity }\end{array}$ & $\begin{array}{c}\text { Zone III } \\
\text { Very high } \\
\text { seismicity }\end{array}$ \\
$\begin{array}{l}\text { Seismic acceleration } \\
\text { coefficient }\end{array}$ & 0.12 & 0.20 & 0.25 & 0.30 \\
$\begin{array}{l}\text { Developed tensile effort } \\
(\mathrm{kN} / \mathrm{m})\end{array}$ & 19.74 & 196.51 & 307.00 & 417.48 \\
$\begin{array}{l}\text { Necessary section } \mathrm{A}_{\text {nec }}\left(\mathrm{cm}^{2}\right) \\
\text { Adopted reinforcement }\end{array}$ & 1.23 & 12.28 & 19.19 & 26.09 \\
Adopted section $\mathrm{A}_{0}\left(\mathrm{~cm}^{2}\right)$ & $14 \phi 10$ & $14 \phi 12$ & $14 \phi 14$ & $14 \phi 16$ \\
\hline
\end{tabular}

Table 2: Results of reinforcement sections for a $1 \mathrm{ml}$ band of the pedestal.

\section{Influence of corrosion on the section of the reinforcements}

To study the effect of pitting corrosion on the section of reinforcements, we consider that the tank is located in a socalled atmospheric zone and we analyse four environments with different levels of aggressiveness to which correspond different chloride ion concentrations $\left(\mathrm{C}_{\mathrm{s}}\right.$ ) (see Tab. 3). In this so-called atmospheric zone, the reservoir is not directly exposed to seawater; wind-borne spray is the main source of chlorides [26]. The data used for the corrosion model are summarized in Tab. 4, for a Portland cement with a content of $400 \mathrm{~kg} / \mathrm{m}^{3}$.

\begin{tabular}{clc}
\hline Environment & \multicolumn{1}{c}{ Description } & $\mathrm{C}_{\mathrm{s}}\left(\mathrm{kg} / \mathrm{m}^{3}\right)$ \\
1 & Environment of low aggressiveness & 1.80 \\
2 & Environment of moderate aggressiveness & 3.50 \\
3 & Environment of high aggressiveness & 5.30 \\
4 & Environment of extreme aggressiveness & 7.40 \\
\hline
\end{tabular}

Table 3: Average values of the parameters $\left(\mathrm{C}_{\mathrm{s}}\right)$ depending on the environment [27]. 


\begin{tabular}{lccc}
\hline Variable & Units & Values & Reference \\
Ambient temperature $\mathrm{T}$ & $\mathrm{K}$ & $25+273$ & {$[21]$} \\
Resistivity of the concrete cover $\mathrm{R}_{\mathrm{c}}$ & $\mathrm{Ohm}$ & 1500 & {$[21]$} \\
Diffusion coefficient $\mathrm{D}_{0}$ & $\mathrm{~m}^{2} / \mathrm{s}$ & $7 \cdot 10-12$ & {$[15]$} \\
Coefficient $\alpha$ & - & 5.65 & {$[28]$} \\
Critical concentration of chlorides $\mathrm{C}_{\mathrm{cr}}$ & $\mathrm{kg} / \mathrm{m}^{3}$ & 0.5 & {$[15]$} \\
Factor ke & - & 0.676 & {$[15]$} \\
Aging factor $\mathrm{n}$ & - & 0.65 & {$[15]$} \\
Test type factor $\mathrm{k}_{\mathrm{t}}$ & - & 0.832 & {$[15]$} \\
Factor $\mathrm{k}_{\mathrm{c}}(28$ days $)$ & - & 4.445 & {$[15]$} \\
Cure time $\mathrm{t}_{0}$ & days & 28 & {$[15]$} \\
\hline
\end{tabular}

Table 4: The used parameters in corrosion model.

The results of the pitting corrosion initiation time, obtained for the different considered environments and for a concrete cover equal to $40 \mathrm{~mm}$, are presented in Tab. 5. These results show that the initiation of corrosion is very sensitive to the aggressiveness of the surrounding environment, which decreases considerably as its moves from an environment of low aggressiveness to an extreme aggressiveness. Except for the low-aggressivity environment, the reservoir's lifetime is above the provisional lifetime of a civil engineering structure (50 to 100 years) [26].

\begin{tabular}{lc}
\hline Environment aggressiveness & $\mathrm{t}_{\text {ini }}$ (years) \\
Environment of low aggressiveness & 213.0459 \\
Environment of moderate aggressiveness & 38.3382 \\
Environment of high aggressiveness & 17.9740 \\
Environment of extreme aggressiveness & 10.8350 \\
\hline
\end{tabular}

Table 5: Corrosion initiation time values for each environment.

The evolution over time of the residual section of reinforcement $A_{s}(t)$, of the most tense unit band, after corrosion is shown in Fig. 5 for the different environments and for each seismic zone. We note that the intersection of the residual section of reinforcement with the necessary section corresponds to the critical threshold beyond which this residual section becomes smaller than the necessary section, thus causing the failure of the structure. This critical threshold therefore defines the lifetime of the tank.

(a) Zone I

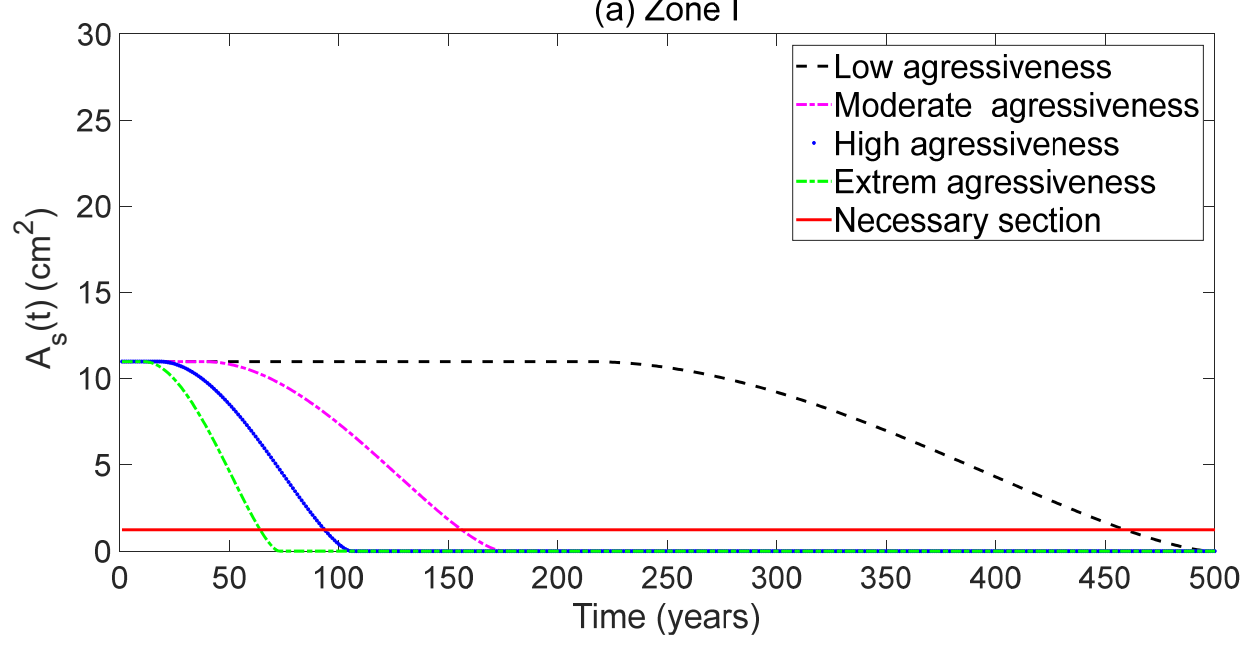


(b) Zone lla

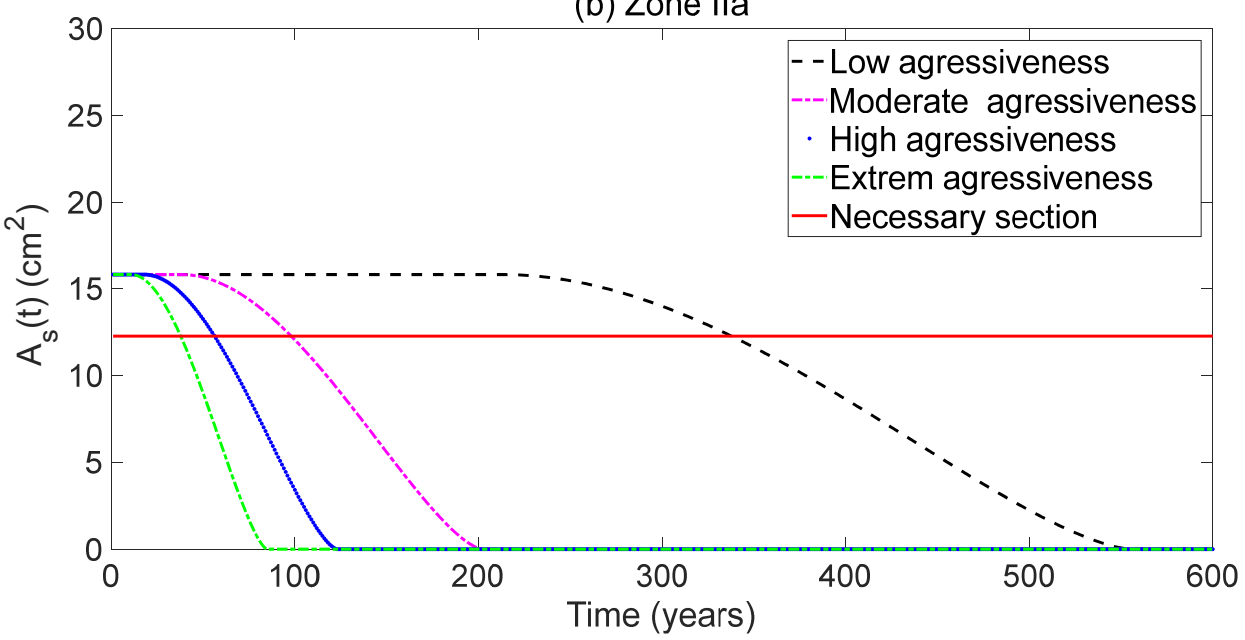

(c) Zone Ilb

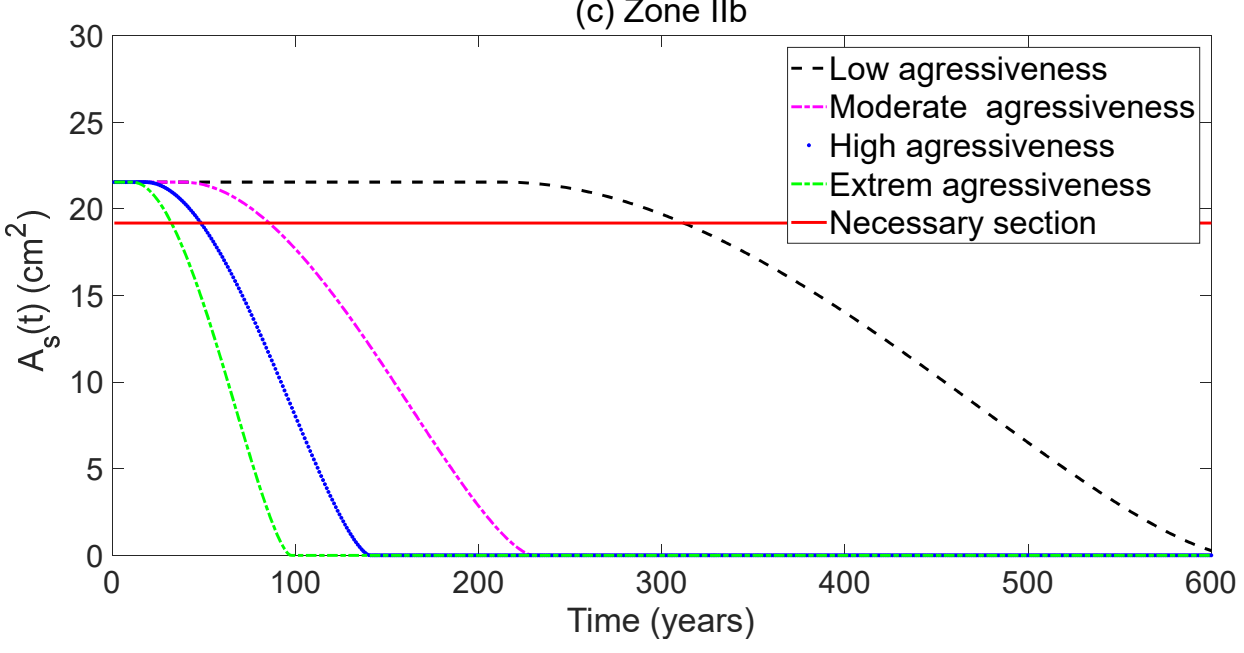

(d) Zone III

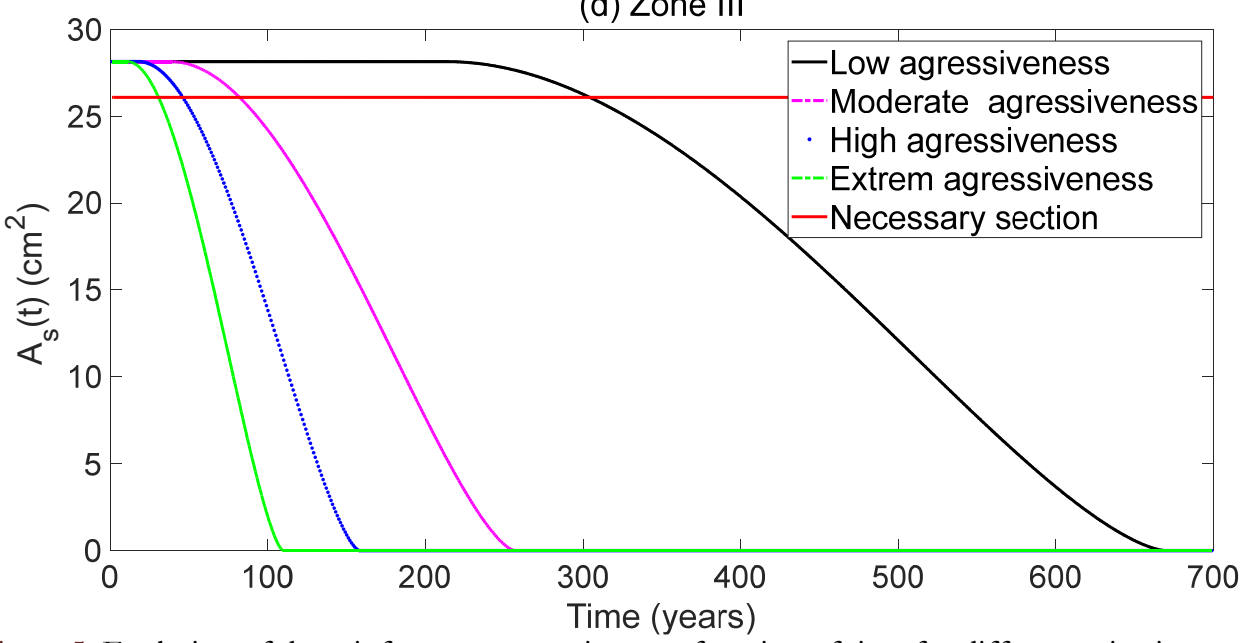

Figure 5: Evolution of the reinforcements section as a function of time for different seismic zones. 
Based on the estimate of Val et al. [26], we propose in Tab. 6 a classification of reservoir life, divided into three levels of safety.

\begin{tabular}{ccccc}
\hline Safety level & Red & Orange & Green \\
Lifetime ( years) & $1-49$ & $50-100$ & $\geq 100$ \\
Estimated lifetime & Critical & Good & Very good \\
\hline
\end{tabular}

Table 6: Classification of service life.

From Fig. 4, we extract the lifetime of the tank as a function of the environment aggressiveness and the seismic zone (Tab. 7). We note that the reservoir has a lifetime far beyond the provisional lifetime in an environment of low and moderate aggressiveness for any seismic zone, and in an environment of high aggressiveness for a low seismicity zone (Fig.5.a). This lifetime decreases significantly in a high aggressiveness environment and moves away from its provisional lifetime dictated by standards in an environment of extreme aggressiveness in medium, high and very high seismicity zones (Fig.5.b, Fig.5.c and Fig.5.d).

\begin{tabular}{lcccc}
\cline { 2 - 4 } & \multicolumn{2}{c}{ Aggressiveness rate } & Extreme \\
seismic zone & Low & Moderate & High & 63 \\
Zone I & 460 & 155 & 94 & 39 \\
Zone IIa & 338 & 100 & 59 & 33 \\
Zone IIb & 314 & 91 & 52 & 30 \\
Zone III & 306 & 87 & 50 & 30 \\
\hline
\end{tabular}

Table 7: Tank lifetime as a function of the environment aggressiveness and the seismic zone.

The results presented above are obtained for fixed values of the calculation parameters for reinforcement's corrosion, such as concrete cover, diffusion coefficient, critical concentration of chloride ions, environment temperature and concrete resistivity. In order to distinguish between parameters that promote the initiation and propagation of corrosion as well as the handicapping parameters, we are interested, in what follows, in the study of the influence of each of these parameters on the lifetime of the elevated tank.

\section{Effect of concrete cover}

The evolution of the initiation time as a function of the concrete cover is shown in Fig. 6 and this for different levels of aggressiveness of environments. The results show that the initiation time increases with the increase in concrete cover, regardless of the considered environment, which clearly explains why the concrete cover has a handicapping effect on the ability of the chloride ions to diffuse in the concrete. Thus, by increasing the value of the concrete cover, we can increase the initiation time and thus increase the life of the tank. However, this increase is less pronounced in environments of high aggression and even less so in environments of extreme aggression.

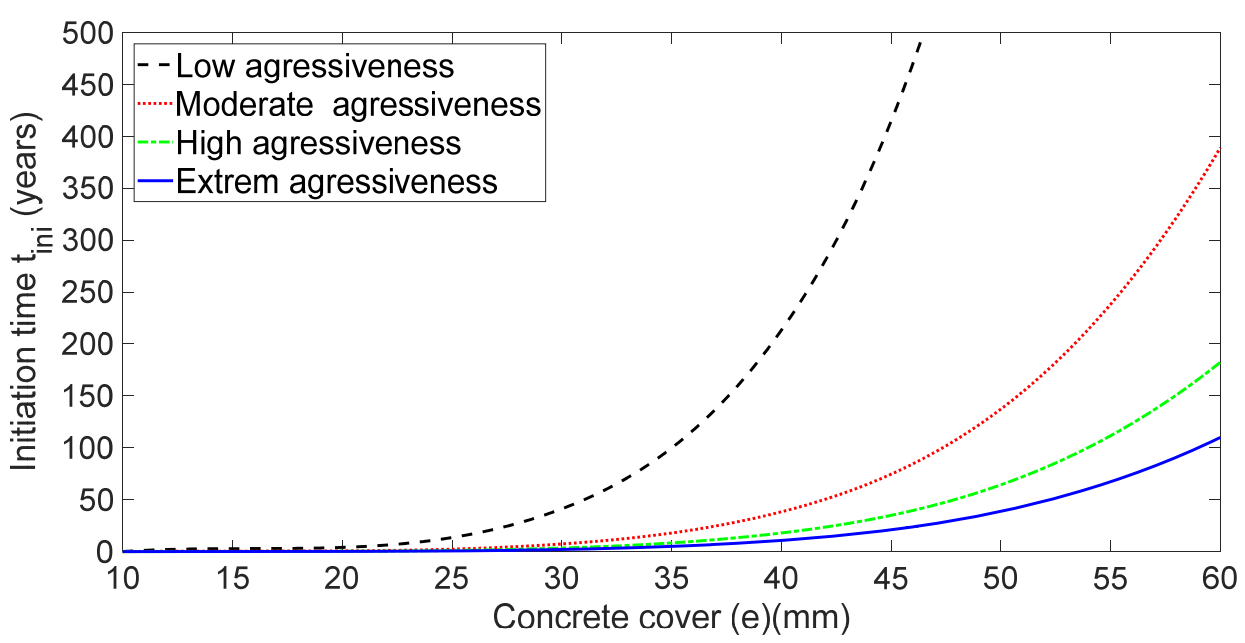

Figure 6: Evolution of initiation time as a function of concrete cover, for different environments. 
In practice, and as a measure of constructive dispositions, the civil engineer refers to the French standards BAEL 99 [29], to fix the concrete cover according to the aggressiveness of the environment, as shown in Tab. 8. The initiation time for each concrete cover recommended by the BAEL [29], and deduced from Fig. 6, is very short, especially in environments of high and low aggressiveness. We conclude that these concrete covers are insufficient to protect the reinforcements from the penetration of chloride ions and therefore from corrosion.

\begin{tabular}{clccc}
\hline Environment & \multicolumn{1}{c}{ Description } & $\mathrm{C}_{\mathrm{s}}\left(\mathrm{kg} / \mathrm{m}^{3}\right)$ & $\mathrm{e}(\mathrm{mm})$ & $\mathrm{t}_{\text {ini }}(\mathrm{years})$ \\
1 & Environment of low aggressiveness & 1.8 & 10 & 0,1 \\
2 & Environment of high aggressiveness & 5.30 & 30 & 3 \\
3 & Environment of extreme aggressiveness & 7.40 & 50 & 39 \\
\hline
\end{tabular}

Table 8: Average values of the parameters (Cs and e) depending on the environment [26, 28].

The evolution over time of the residual section of reinforcement $A s(t)$ of the most tense unit band, for the environments considered and for the different concrete covers recommended by BAEL [29], is shown in Fig. 7 for two seismic zones (IIa and III). By analyzing the critical corrosion threshold, we find that the corrosion propagation is accelerated and that the tank enters into failure at less than 10 years and 30 years respectively in the low and high aggressiveness environment; which confirms that the concrete covers recommended by the BAEL [29] are insufficient to protect the structure. Inversely, the concrete cover of $5 \mathrm{~cm}$ recommended in an extremely aggressive environment is sufficient to ensure the provisional lifetime of such structure, given that the critical threshold was recorded at 75 years. Since the results observed for the two seismic zones are similar, we have chosen the very high zone for the rest of our analysis.

(a) Zone Ila

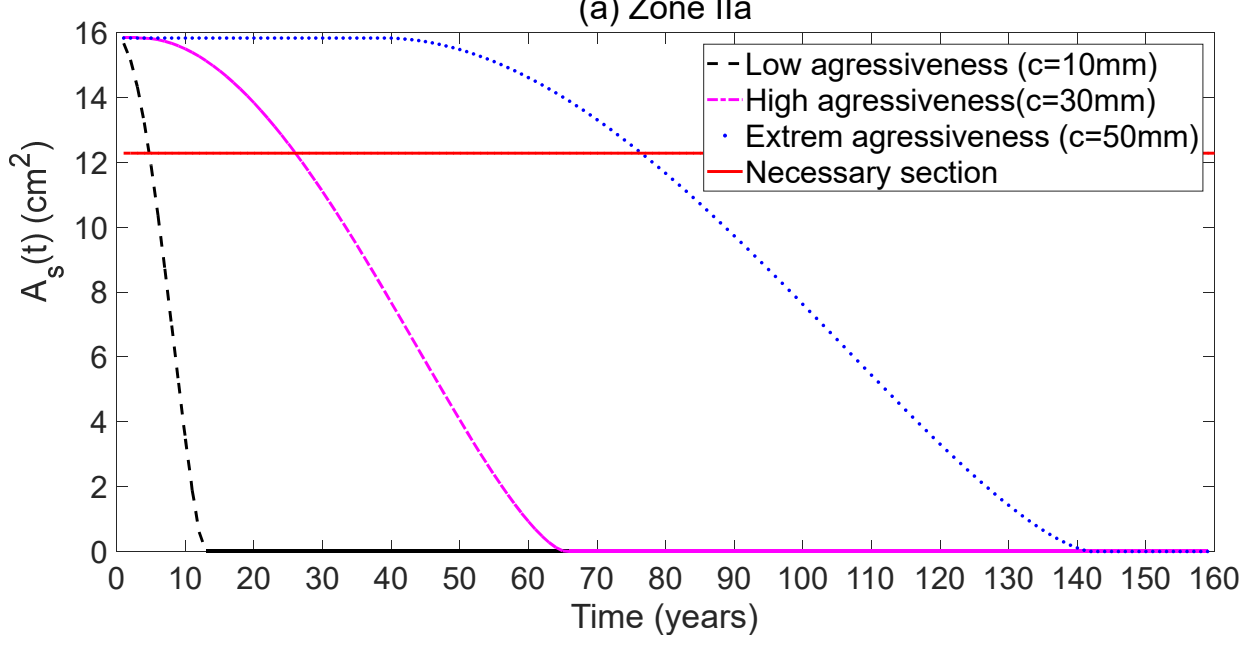

(b) Zone III

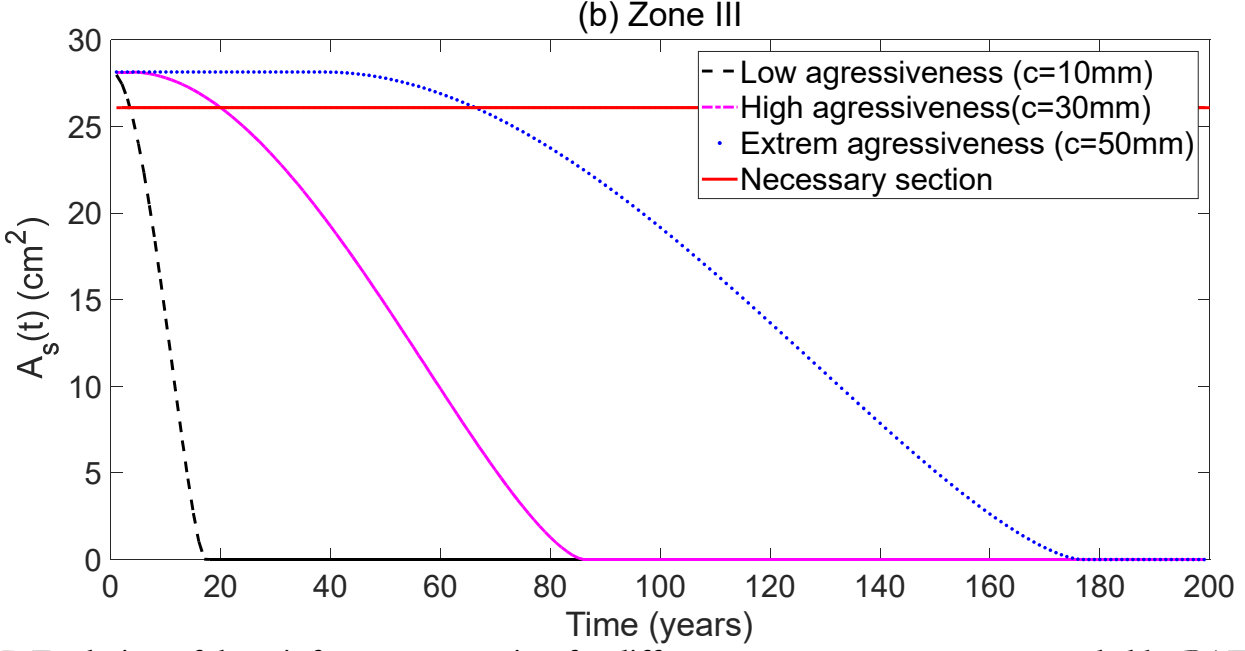

Figure 7: Evolution of the reinforcements section for different concrete covers recommended by BAEL [29]. 


\section{Effect of the diffusion coefficient}

To study the effect of the diffusion coefficient noted $\mathrm{D}_{0}$, we refer to the values defined by Duracrate [14] according to the cement content and the ratio W/C. These values vary from $200 \mathrm{~mm}^{2} /$ year to $800 \mathrm{~mm}^{2} /$ year for good and bad concrete respectively. The evolution of the initiation time as a function of the diffusion coefficient is illustrated in Fig. 8 for the considered environments and for a concrete cover of $40 \mathrm{~mm}$. We notice that for a diffusion coefficient lower than 500 $\mathrm{mm}^{2} /$ year, the initiation time decreases with the increase in the aggressiveness of the environment. However, above 500 $\mathrm{mm}^{2} /$ year, and except for the low aggressiveness environment, corrosion initiation is immediate in the other three environments. Indeed, the research work of Hobbs et al. [30] has shown that the diffusion coefficient is mainly a function of the W/C ratio, which has a very great influence on the porosity of concrete. More the diffusion coefficient is important, more the concrete's porosity is greater, thus facilitating the penetration of aggressive elements to accelerate the corrosion of the reinforcement [31].

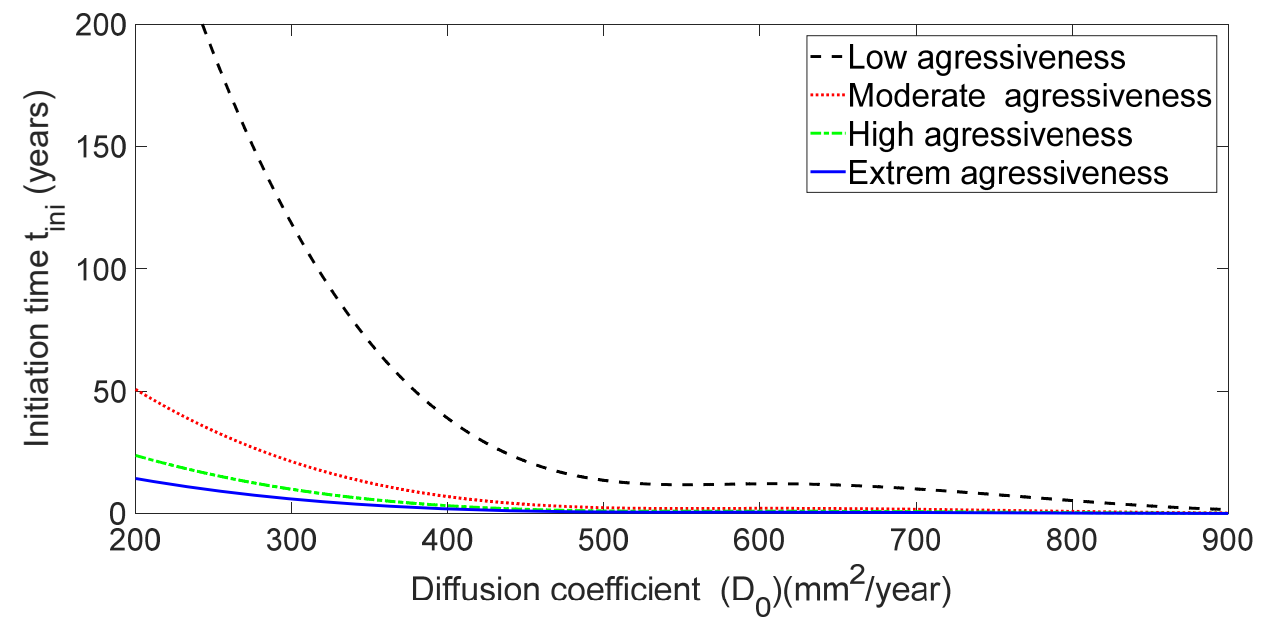

Figure 8: Effect of diffusion coefficient and chloride ion concentration on corrosion initiation time.

The evolution of the residual section of reinforcements over time for different diffusion coefficients is shown in Fig. 9 for a moderate and aggressiveness environment. We find that the propagation of corrosion decreases with reduction of diffusion coefficient. The lifetime of the tank is approximately 100 years in the moderate aggressiveness environment (Fig.9.a). However, in environment of extreme aggressiveness (Fig.9.b), it stays below the provisional duration of 50 years, regardless of the values of the diffusion coefficient. This explains why, in an aggressive environment, in order to increase the lifetime of the structure it is necessary to reduce the capillary porosity of the concrete by reducing the W/C ratio.

In practice, careful curing of the concrete considerably improves the waterproofing of the surface.

(a) Environment of moderate aggressiveness

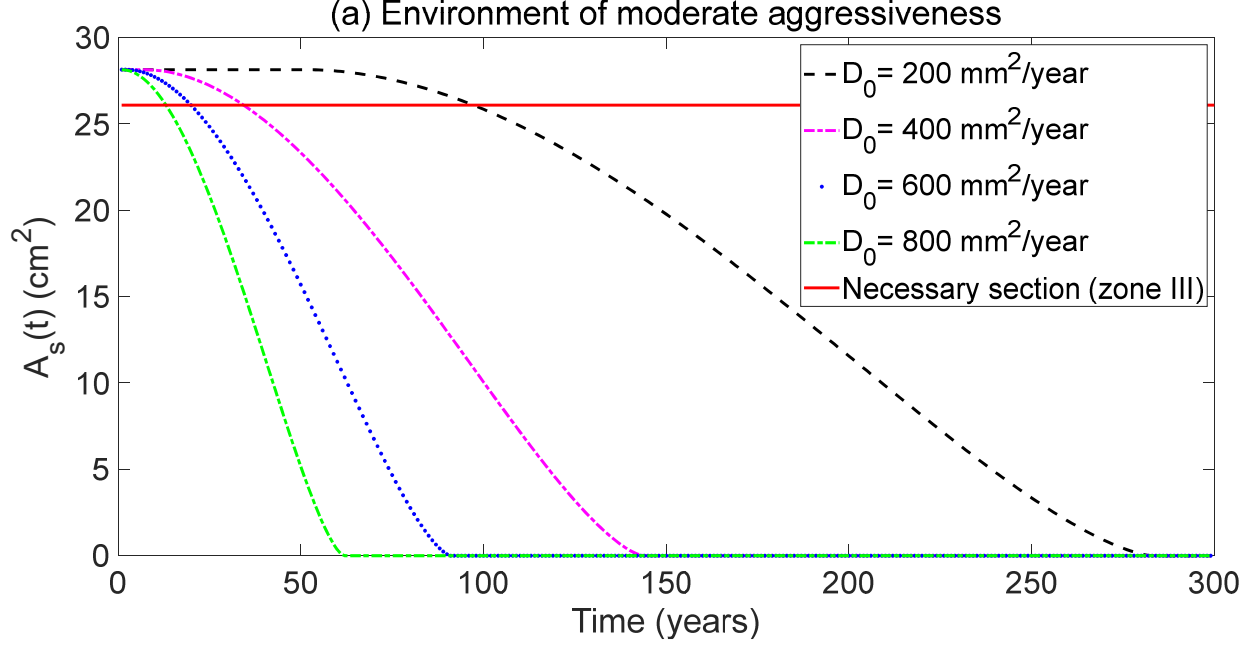


(b) Environment of extreme aggressiveness

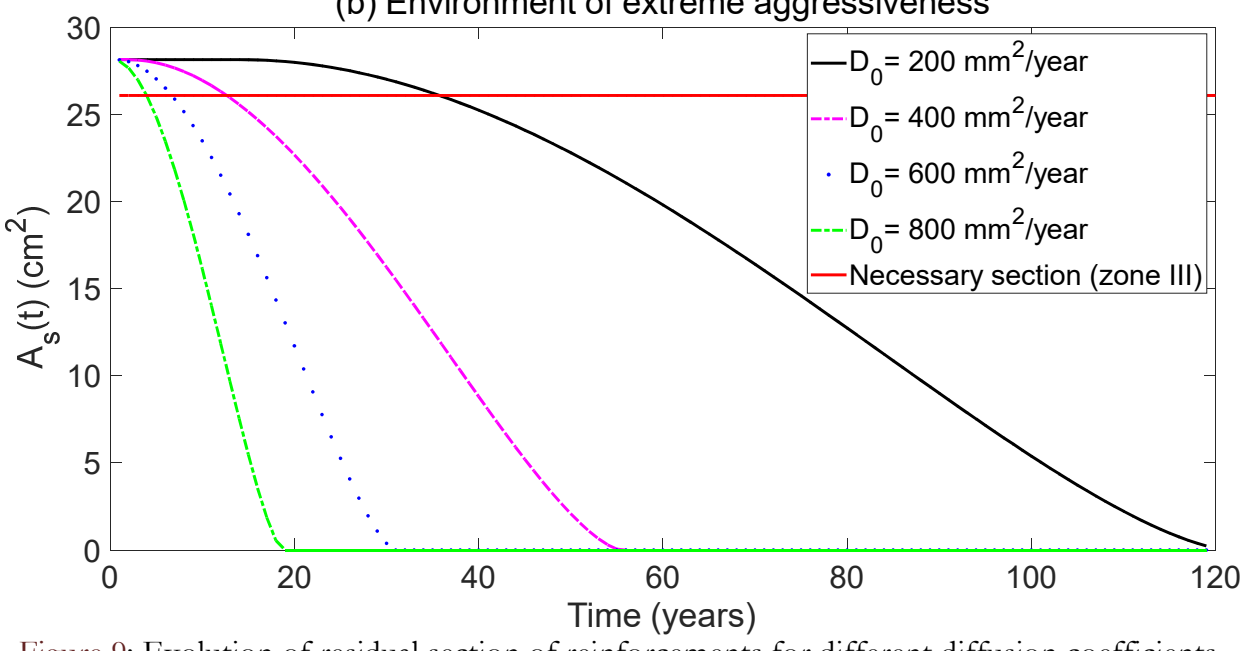

Figure 9: Evolution of residual section of reinforcements for different diffusion coefficients.

\section{Influence of concrete quality}

The quality of the concrete is linked to the cement content. The higher is the cement content, more concrete strength is increased. In order to study the impact of cement content on the initiation time of a pitting corrosion and on the lifetime of the tank, we combined two parameters that are depending on the cement content according to the literature, namely the diffusion coefficient and the critical concentration of chloride ions. To this effect, Duracrate [15] proposes values of the diffusion coefficient as a function of cement content (Tab. 9). As for the maximum content of chloride ions $\left(\mathrm{C}_{\mathrm{cr}}\right)$, it is given according to the cement content, by the formula proposed by the French standard [32]:

$$
C_{c r}=0.2 \% C
$$

The initiation time (Tab. 9) is calculated for each cement content considering a concrete cover of $40 \mathrm{~mm}$ and a moderate aggressiveness environment. The initiation time increases with the cement content and the critical concentration of chlorides ions. This increase corresponds to a decrease in the diffusion coefficient. The latter decreases as the quality of the concrete increases, thus limiting the penetration of chlorides and consequently the risk of corrosion.

\begin{tabular}{lccccc}
\hline Nature of the concrete & $\begin{array}{c}\mathrm{C} \\
\left(\mathrm{kg} / \mathrm{m}^{3}\right)\end{array}$ & $\begin{array}{c}\mathrm{D}_{0} \\
\left(10^{-12} \mathrm{~m}^{2} / \mathrm{s}\right)\end{array}$ & $\begin{array}{c}\mathrm{e} \\
(\mathrm{mm})\end{array}$ & $\begin{array}{c}\mathrm{C}_{\mathrm{cr}} \\
\left(\mathrm{kg} / \mathrm{m}^{3}\right)\end{array}$ & $\begin{array}{c}\mathrm{t}_{\text {ini }} \\
\text { (years })\end{array}$ \\
Poor concrete & 300 & 15 & 40 & 0.6 & $\mathbf{6 . 4 4}$ \\
Ordinary concrete & 350 & 10 & 40 & 0.7 & $\mathbf{2 9 . 7 4}$ \\
good concrete & 400 & 7 & 40 & 0.8 & $\mathbf{1 1 7 . 7 2}$ \\
\hline
\end{tabular}

Table 9: Average values of the critical concentration of chlorides ions and the diffusion coefficient for each quality of concrete [15, $32]$.

The evolution of the initiation time as a function of the concrete cover is illustrated in Fig. 10 for different qualities of concrete. We notice that beyond a concrete cover of $30 \mathrm{~mm}$, the initiation time increases as the concrete cover increases. Furthermore, this increase is more pronounced for better quality concrete. However, for a concrete cover smaller than 30 $\mathrm{mm}$, corrosion is immediately initiated for the different qualities of concrete. Thus, the initiation of corrosion of the reinforcements is subordinated to the use of an adequate concrete cover, and to a better quality of the concrete, which is governed by the increase of the cement content, the increase of the critical concentration and the decrease of the diffusion coefficient.

Fig. 11 show the temporal variation of the residual section of reinforcement for different qualities of concrete in a moderate and extreme environment. We notice that the propagation of corrosion is slowed down as the cement content is increased. However, for the same quality of concrete, the lifetime of the tank in a moderate aggressiveness environment (Fig.11.a) is twice as long as that of a tank evolving in an extreme aggressiveness environment (Fig.11.b). For this reason, Fascicule 74 [23] recommends a minimum cement content of $400 \mathrm{~kg} / \mathrm{m}^{3}$ for the concrete used to build tanks. 


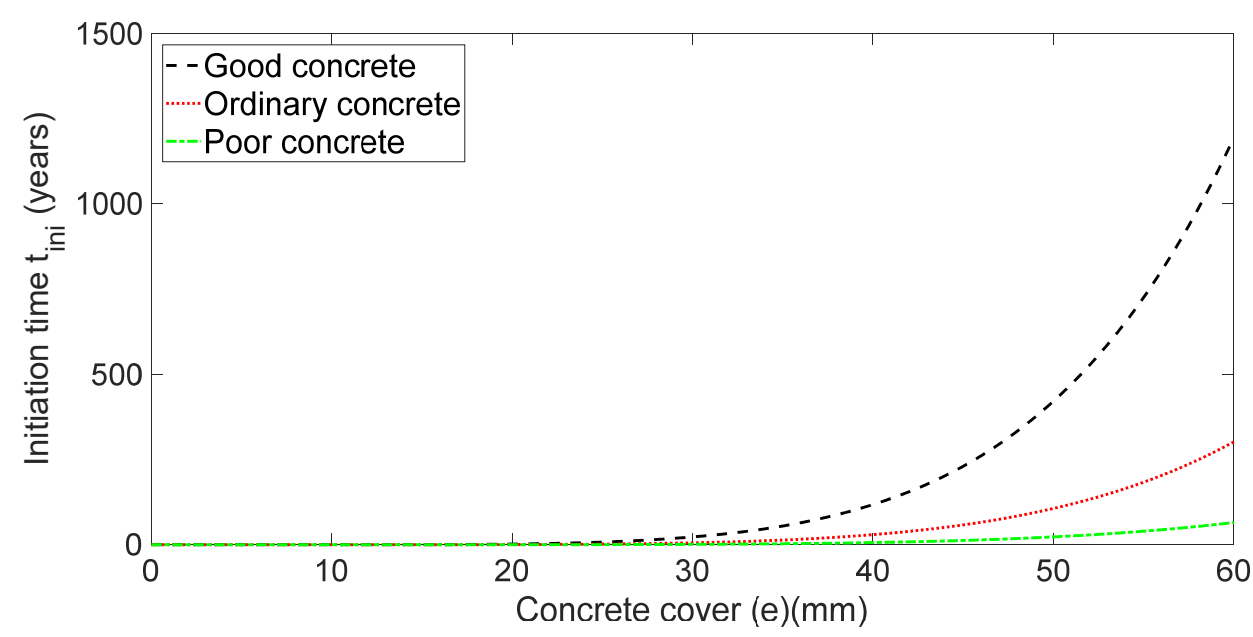

Figure 10: Effect of concrete cover, and quality of concrete on initiation time of corrosion.

(a) Environment of moderate aggressiveness

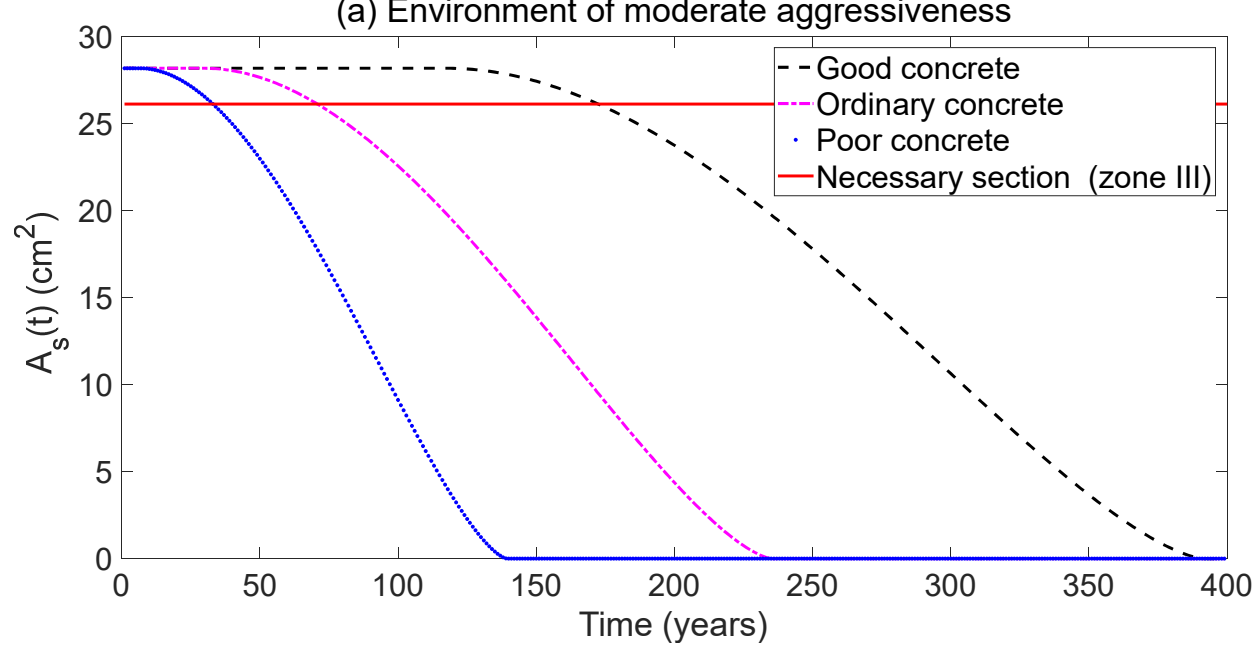

(b) Environment of extreme aggressiveness

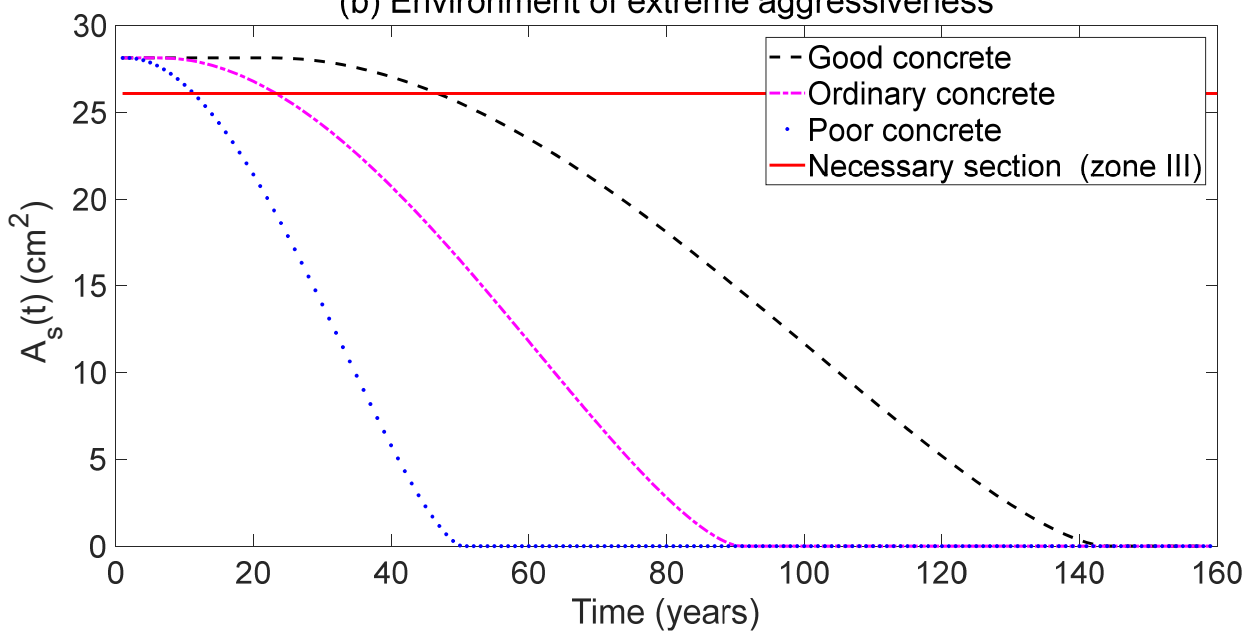

Figure 11: Evolution of residual section of reinforcements as a function of time for different cement contents.

\section{Influence of critical concentration of chlorides}

The presence of $\mathrm{Cl}^{-}$ions in the vicinity of steel surfaces does not automatically induce corrosion. Accumulation of chlorides until the critical concentration is reached in the vicinity of the reinforcements is necessary for the passive layer 
that protects the steel to fail and corrosion to initiate [12]. Fig. 12 shows the initiation time of corrosion as a function of the critical concentration of chlorides ions in the vicinity of the reinforcements for environments of different aggressiveness. The initiation time increases as the critical concentration increases, thus slowing down the corrosion initiation. However, we notice that this increase is less pronounced in environments of high and extreme aggressiveness, whereas for these two environments the critical concentration of chlorides ions is important.

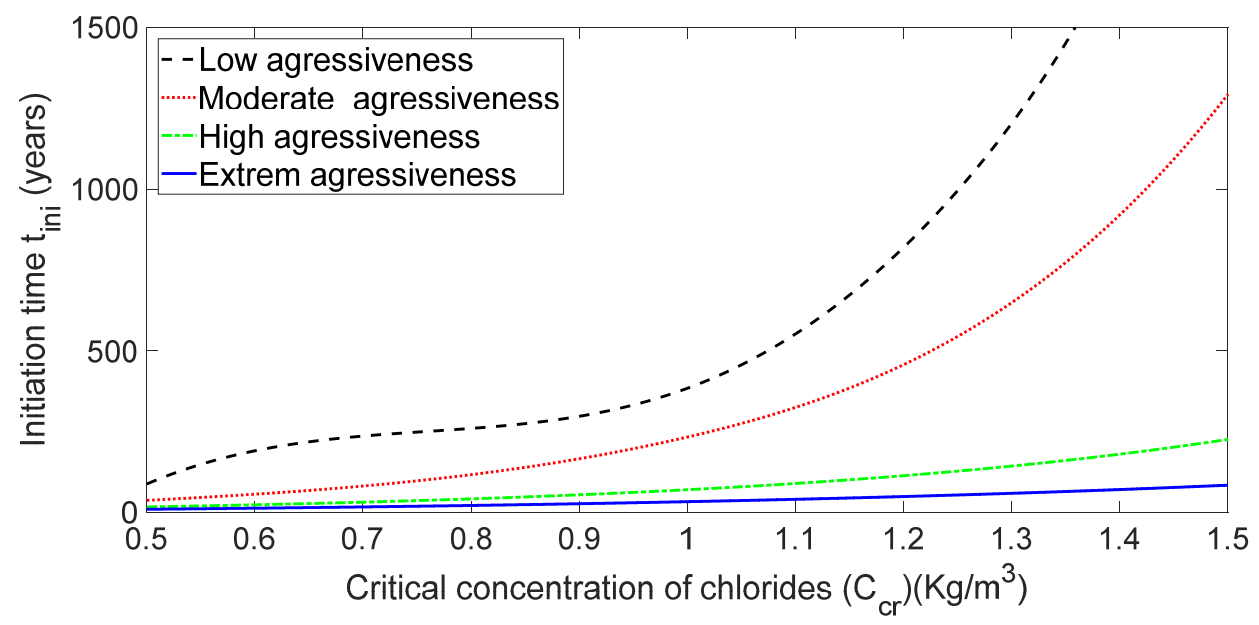

Figure 12: Evolution of the residual section of reinforcements for different values of the critical concentration.

The evolution of the residual section of reinforcement for different critical chlorides ions concentration values is shown in Fig. 13 for moderate and extreme environment. We find that the lifetime of the tank is all the longer as the critical concentration of chloride ions is important. However, in the environment of extreme aggressiveness (Fig.13.b), the lifetime still very short compared to the environment of moderate aggressiveness (Fig.13.a). We notice that for critical concentrations of $0.50 \mathrm{~kg} / \mathrm{m}^{3}$ and $0.75 \mathrm{~kg} / \mathrm{m}^{3}$, the provisional lifetime is not reached.

\section{Influence of the temperature}

It is known that temperature promotes the corrosion process [3]. According to Liu and Weyers [21], an increase in temperature increases the speed of corrosion. This phenomenon can be explained by the fact that the anodic (oxidation of steel components) and cathodic (reduction of protons in an acid environment) processes are thermally activated. This results in an exchange current, i.e. a corrosion rate increasing with temperature. An increase in temperature from 10 to $20^{\circ} \mathrm{C}$ multiplies by two the corrosion rate in an active corrosion situation. For this reason, we judged it useful to evaluate the corrosion rate at different temperatures for different environments (Fig. 14). We notice that the corrosion rate increases with the increase of temperature. This promotes the propagation of corrosion and increases the diffusivity of chlorides ions. For a given temperature, the corrosion rate is more pronounced in high and extreme aggressiveness environments.

The evolution of the residual section of reinforcements in a moderate and extreme environment is illustrated in Fig. 15 for different temperature values. The curves show that the increase of temperature accelerates the propagation of corrosion following the increase of the diffusivity of chlorides, especially in an extreme aggressiveness environment (Fig.15.b) where the presence of chlorides is important, which induces a reduction in the lifetime of the structure.

\section{Influence of concrete resistivity}

The resistivity of concrete represents its capacity to prevent electrons from moving and significantly affects the corrosion of reinforcements in concrete [33]. This depends on the composition of the concrete interstitial solution, its microstructure (pore size and pore distribution), humidity, salt content, and ambient temperature [34]. Fig. 16 shows the influence of concrete resistivity on the corrosion rate, for different rates of aggressiveness and for a temperature of $25{ }^{\circ} \mathrm{C}$. We find that corrosion of the reinforcement increases as the electrical resistivity of the concrete decreases. However, for a given resistivity, the corrosion rate is much more important in the environment of high and extreme aggressiveness and tends towards zero in the environment of low aggressiveness. In an aggressive environment, even if the resistivity of the concrete is high, the density of chloride ions remains always high. 

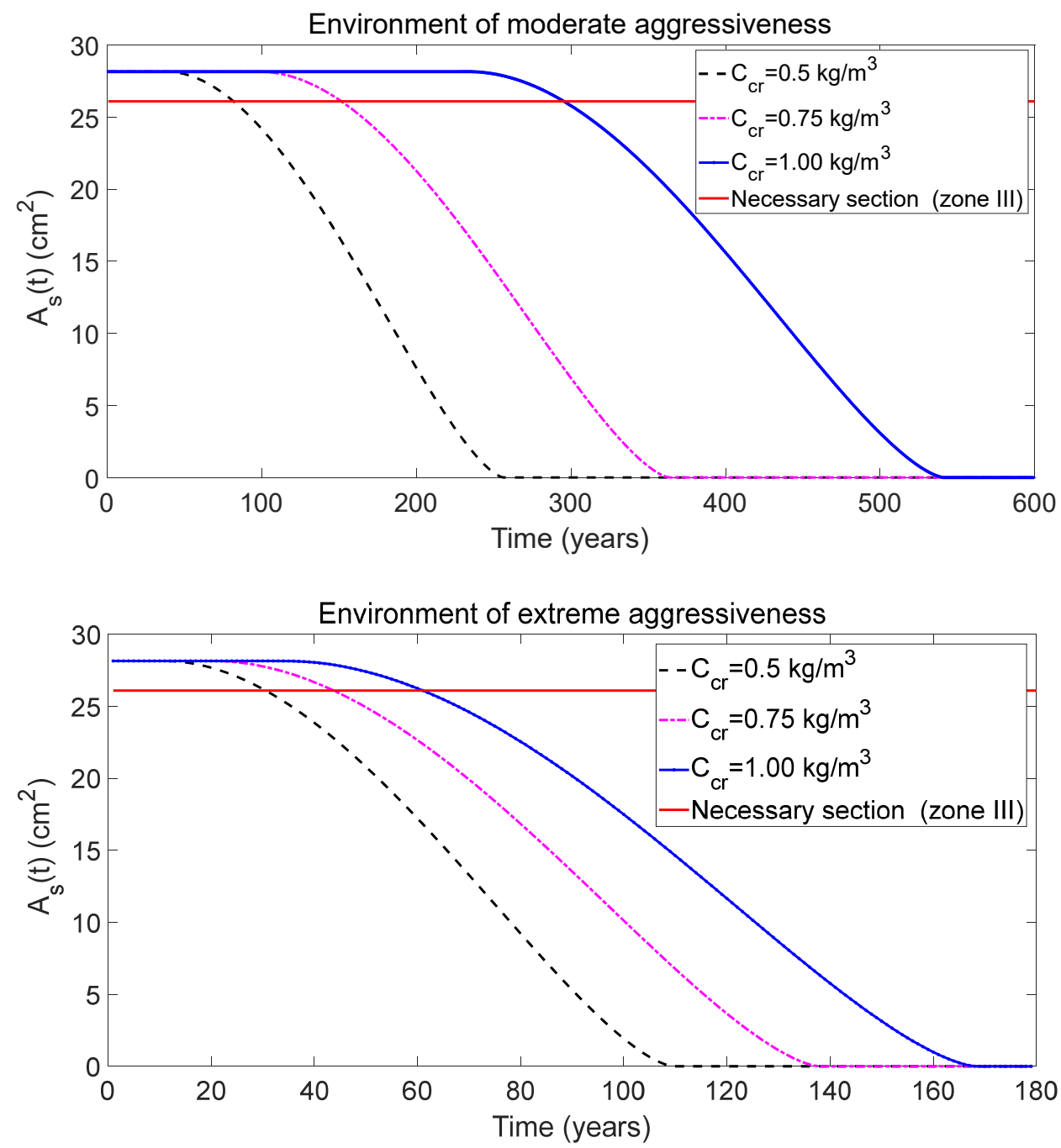

Figure 13: Evolution of the residual section of reinforcements for different values of the critical concentration.

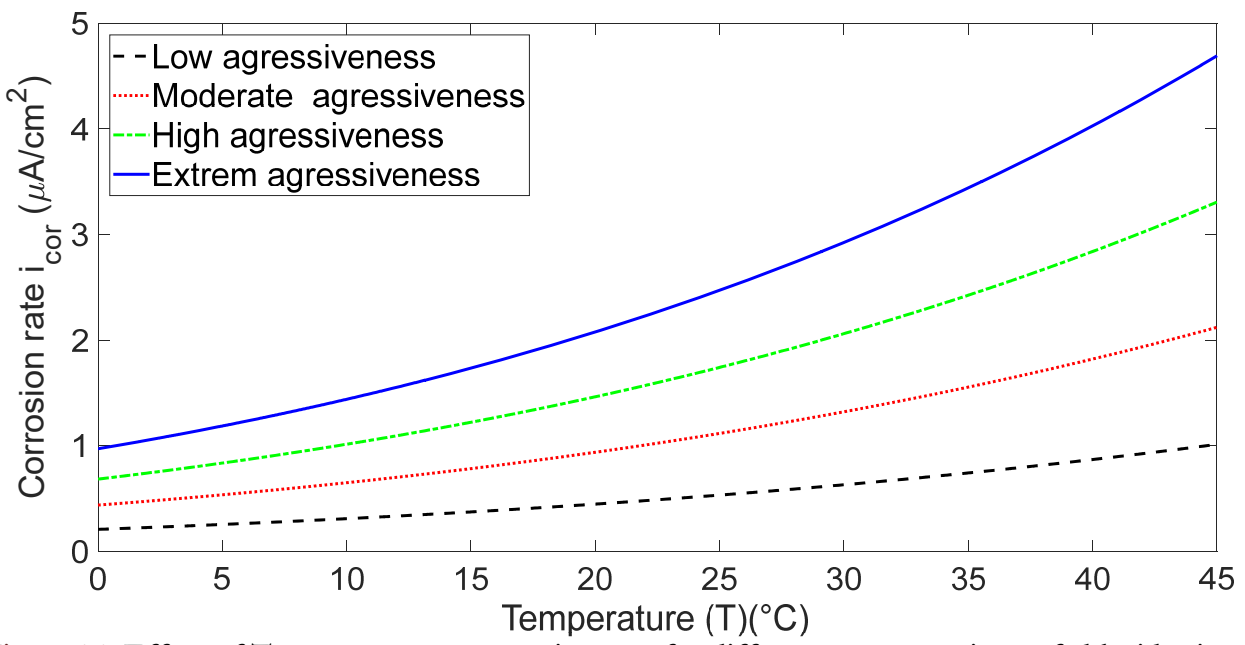

Figure 14: Effect of Temperature on corrosion rate for different concentrations of chlorides ions. 
(a) Environment of moderate aggressiveness

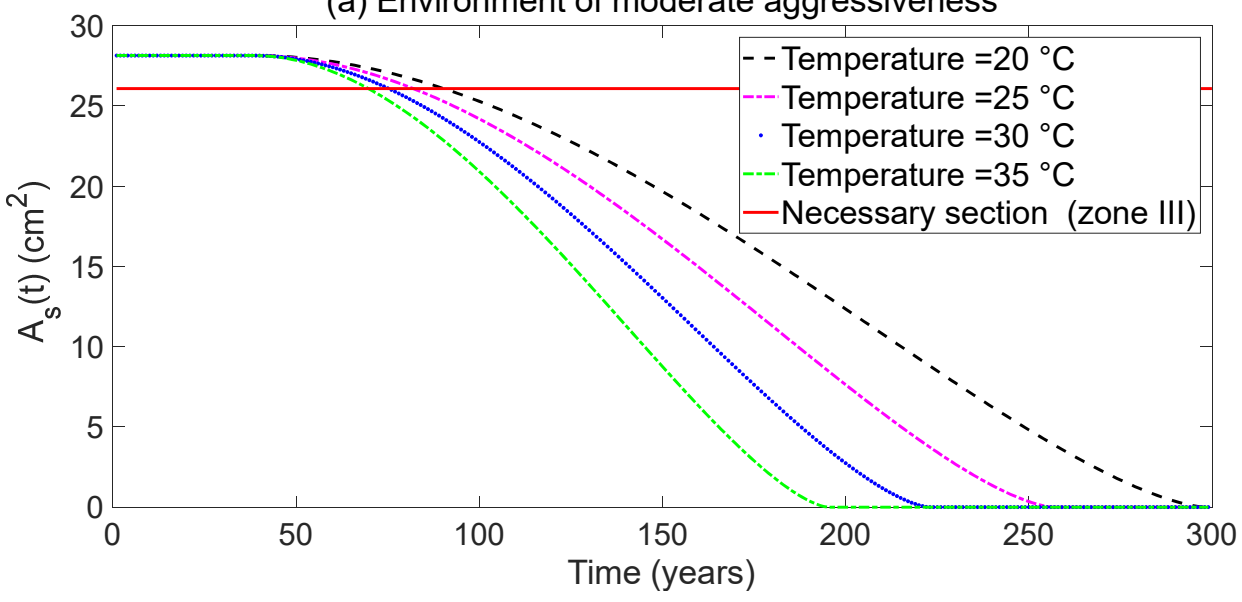

(b) Environment of extreme aggressiveness

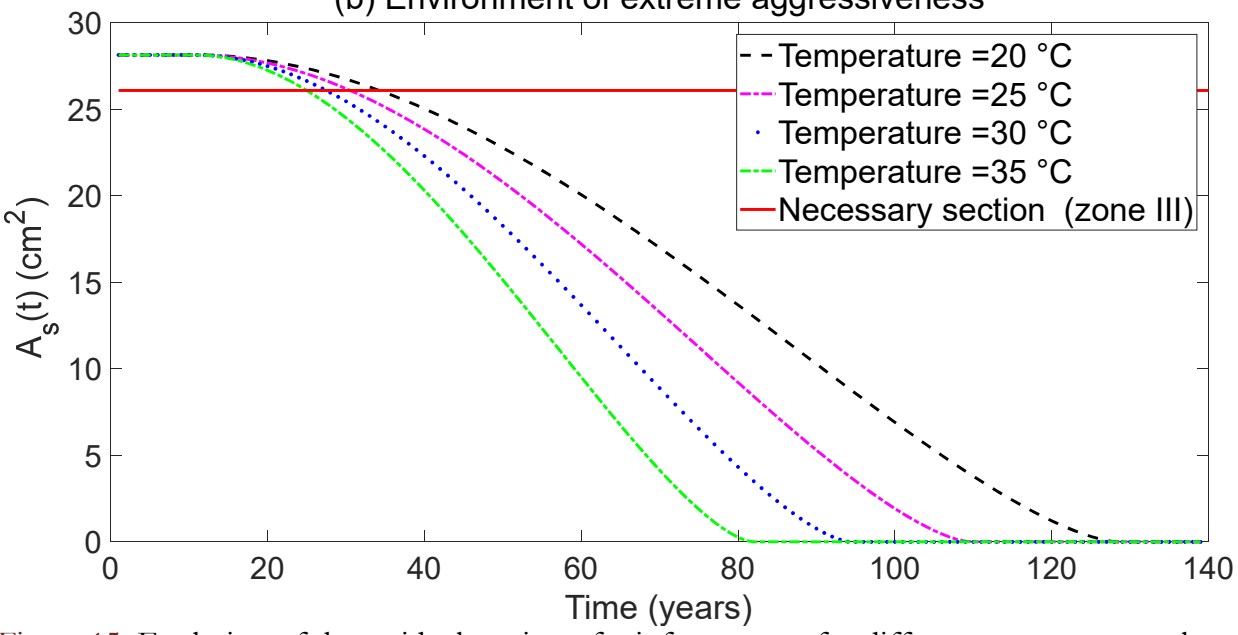

Figure 15: Evolution of the residual section of reinforcements for different temperature values.

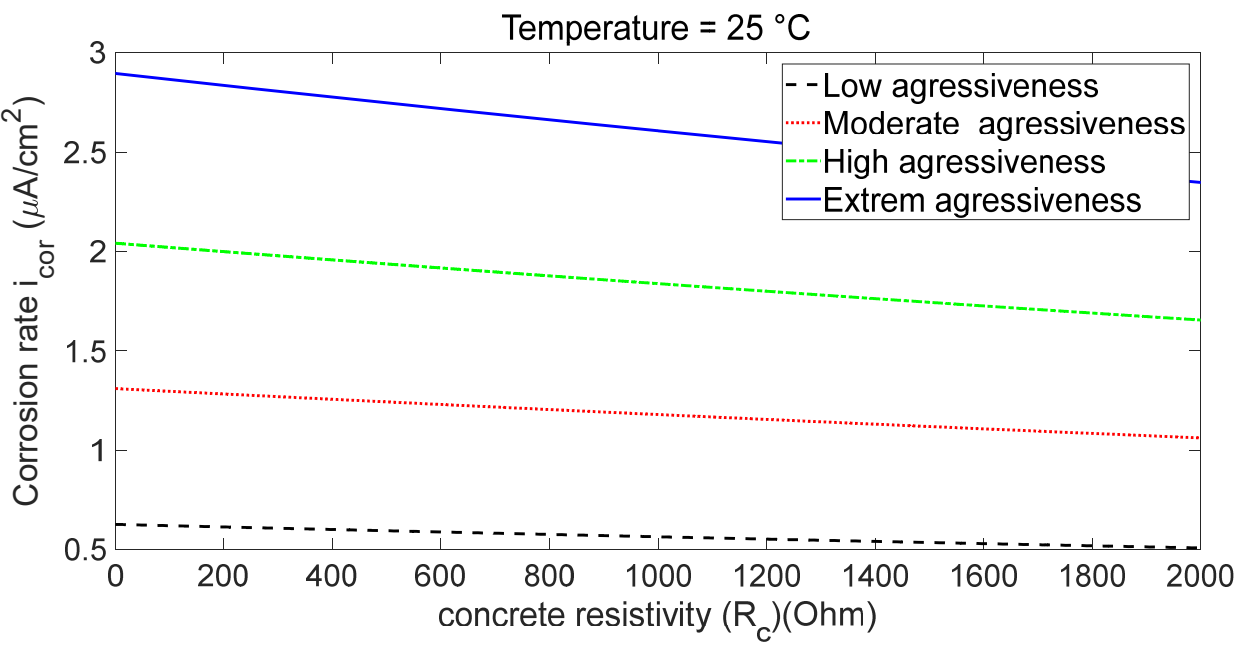

Figure 16: Effect of the concrete resistivity and the concentration of chlorides ions on the corrosion rate.

The evolution of the residual section of reinforcement for different resistivity values is shown in Figs. 17 for moderate and extreme environment. It is noticed that the resistivity of concrete has an handicapping effect on the propagation of 
corrosion. In fact, if the electrical resistivity of concrete is important, the last will be less conductive, and thus the passage of chloride ions will be limited, and the lifetime of the structure will be prolonged. However, it is noticed that in an aggressive environment (Fig.17.b), even if the resistivity of the concrete is quite important, the penetration of chloride ions is still high and the tank lifetime remains less than the provisional duration of 50 years.
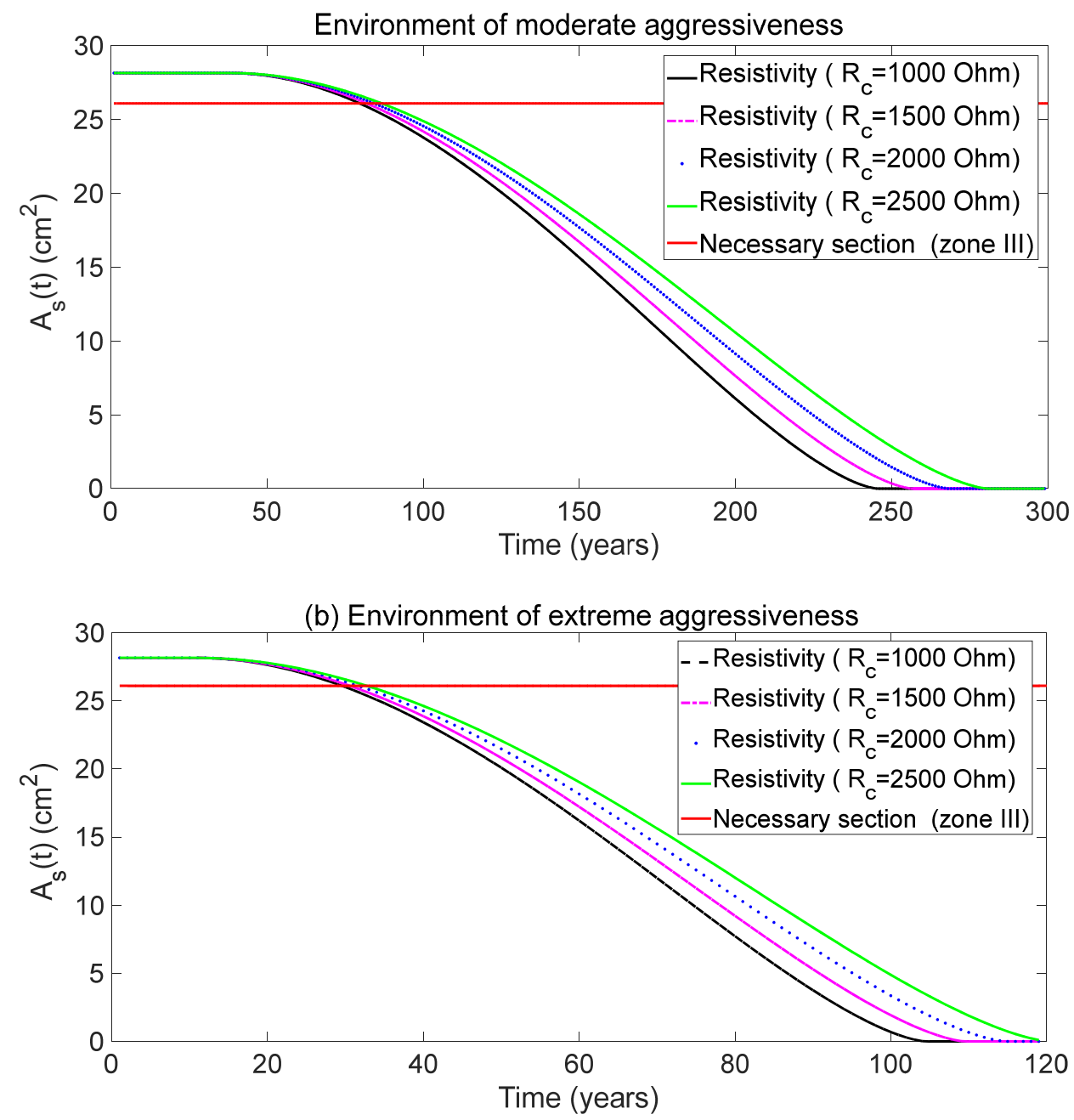

Figure 17: Evolution of the residual section of reinforcements for different resistivity values.

\section{CONCLUSION}

$\mathrm{P}$

itting corrosion of reinforcements is one of the most serious pathologies affecting concrete tanks and leading them to failure. This corrosion induced by the penetration of chloride ions is aggravated by the aggressiveness of the surrounding environment which accelerates its initiation and propagation. Through a deterministic analysis of an elevated concrete tank located in an atmospheric environment, we have shown that in same conditions, the lifetime of the tank decreases considerably, going from a low to an extreme aggressiveness environment, whatever the seismic zone. In addition, a parametric study has shown that concrete cover, cement content, resistivity and the critical concentration of chlorides ions are factors that slow down the initiation and propagation of corrosion. In fact, the results have highlighted the importance of covering in the protection of the reinforcements against the aggressiveness of the environment. Its disabling effect reduces considerably the ability of chloride ions to diffuse in concrete, thus prolonging the corrosion initiation time as well as the lifetime of the structure. However, the covering values recommended by BAEL 99 [29] in an environment of low and high aggressiveness are insufficient for the steels protection against corrosion. The results also showed the importance of respecting the cement content, especially in environments of high and extreme aggressiveness; this justifies the recommendation in Fascicule 74 [23] which imposes a content of $400 \mathrm{~kg} / \mathrm{m}^{3}$ for tanks. As for resistivity, 
this has a direct influence on the conductivity of the concrete as well as on the diffusion of oxygen in the material. Higher is the resistivity of the concrete, more limited is the diffusion of aggressive ions and lower is the corrosion current. However, in an aggressive environment, even if the resistivity of the concrete is high, the density of chloride ions always remains high, hence the necessity to increase the concrete cover. Finally, if the reinforcement in concrete has a low critical concentration of chlorides, the initiation of corrosion is fast, so increasing the critical concentration will lead to a reduction of corrosion. Several studies have shown that the critical concentration is influenced by the quality of the steel. Among parameters favouring the propagation of corrosion, we can mention the temperature and the diffusion coefficient. A high temperature increases the diffusivity of chloride ions, especially in environments of high and extreme aggressiveness, where the concentration of chlorides on the surface of steels is high. In addition, the diffusion coefficient is a parameter linked to the $\mathrm{W} / \mathrm{C}$ ratio; it is all the more important as the porosity of the concrete, facilitating the penetration of aggressive species that subsequently cause corrosion of the reinforcements.

The phenomenon of corrosion is quite complex to be taken lightly, as so many parameters are interdependent, hence the importance of integrating it in standards and readjusting the concrete cover for each environment. It is a necessary to consider, in the design step, certain requirements such as the quality and properties of the concrete composition, its implementation conditions, climatic and environmental conditions. It is also recommended to include these criteria with their variability in design codes as sources of aggression in the definition of exposure classes, in order to design more sustainable structures in aggressive environments.

\section{ACKNOWLEDGEMENTS}

he authors wish to thank the Algerian Ministry of higher education and scientific research for funding the University education research project (PRFU - N A01L02UN150120180002) and Tassili Project (PHC 18MDU121).

\section{DECLARATION OF INTEREST STATEMENT}

n behalf of all authors, the corresponding author states that there is no conflict of interest.

\section{REFERENCES}

[1] Gerengi, H. (2018). The use of dynamic electrochemical impedance spectroscopy in corrosion inhibitor studies, J. Prot. Met. Phys. Chem. Surf, 54(3), pp. 536-540.

DOI: $10.1134 /$ S2070205118030267.

[2] Règlement parasismique algérien (RPA 99/Version 2003). Document technique réglementaire DTR BC 2 48. Centre National de Recherche Appliquée en Génie Parasismique, Ministre de l'Habitat, Alger, Algérie.

[3] Bastidas Arteaga, E. and Stewart, M.G. (2015). Damage risks and economic assessment of climate adaptation strategies for design of new concrete structures subject to chloride-induced corrosion, J. Struct .Saf., 52, pp.40-53. DOI: $10.1016 /$ j.strusafe.2014.10.005.

[4] Hoskin, L.M. and Jacobsen, L.S. (1934). Water Pressure in a tank caused by a simulated earthquakes, J. Bull. Seismol. Soc. Am., 24, pp. 1-32.

[5] Westergaard, H.M. (1933). Water Pressures on Dams During Earthquakes, Trans, ASCE 98., 47, pp. 418-472.

[6] Housner, G.W. (1957). Dynamic pressures on accelerated fluid containers, J. Bull. Seismol. Soc. Am., 47, pp.15-35.

[7] Housner, G.W. (1963). The dynamic behavior of water tanks, J. Bull. Seismol. Soc. Am., 53, pp. 381-387.

[8] Epstein, H.I. (1976). Seismic design of life liquid storage tanks, J. Struct.Div., 102(9), pp. 1659-1673.

[9] Hammoum, H., Bouzelha, K. and Slimani, D. ed., (2016). Seismic risk of RC water storage elevated tanks: Case study, In: Handbook of Materials Failure Analysis with Case Studies from the Chemicals, Concrete and Power Industries, New York, Elsevier Ed., pp. 187-216. DOI: 10.1016/B978-0-08-100116-5.00008-9.

[10] Aliche, A., Hammoum, H. and Bouzelha, K. (2019). Mecano-reliability analysis applied to RC tank under seismic loads according to the Algerian seismic standard, Asian. J. Civ. Eng., 20, pp.395-408. 
DOI: 10.1007/s42107-018-00113-x.

[11] Nguyen, P.T., Bastidas Arteaga, E., Amiri, O. and El Soueidy, C.P. (2017). An Efficient Chloride Ingress Model for Long-Term Lifetime Assessment of Reinforced Concrete Structures Under Realistic Climate and Exposure Conditions, Int. J. Concr. Struct. Mater.,11, pp. 199-213. DOI: 10.1007/s40069-017-0185-8.

[12] Stewart, M.G. and Rosowsky, D.V. (1998). Time-dependent reliability of deteriorating reinforced concrete bridge decks, J.Struct. Saf., 20, pp. 91-109. DOI:10.1016/S0167-4730(97)00021-0.

[13] Aoues, Y. (2008). Optimisation fiabiliste de la conception et de la maintenance des structures. Thèse de Doctorat en Genie Civil, Université Blaise Pascal-Clermont II, France.

[14] Duprat, F. (2006). Reliability of RC beams under chloride-ingress, J. Constr. Build. Mater.,21, pp.1605-1616. DOI: 10.1016/j.conbuildmat.2006.08.002.

[15] Duracrete. (2000). Statistical quantification of the variables in the limit state functions. Tech Rep, The European Union - Brite EuRam III - Contract BRPR-CT95-0132 - Project BE95-1347/R9.

[16] Güneyisi, E.M., Mermerdaş, K., Güneyisi, E. and Gesoglu, M. (2015). Numerical modeling of time to corrosion induced cover cracking in reinforced concrete using soft-computing based methods, J. Mater Struct.,48, pp.17391756. DOI: $10.1617 / \mathrm{s} 11527-014-0269-8$.

[17] Tuutti, K. (1982). Corrosion of steel in concrete, Stockholm: Swedish Cement and Concrete Research Institute, CBI Forsking Research Report.,82(4).

[18] National Laboratory of Civil Engineering LNEC E 465. (2009). Resistance of concrete to carbonation. Predicted and measured values in natural exposure, Lisbon, Portugal., 8.

[19] Otieno, M., Beushausen, H. and Alexander, M. (2012). Prediction of corrosion rate in reinforced concrete structures a critical review and preliminary results, J. Mater. Corros., 63(9). DOI:10.1002/maco.201106282.

[20] Bouzelha, K., Amazouz, L., Miloudi, N. and Hammoum, H. (2019). Temporal analysis of the performance of a RC storage tank considering the corrosion. First International Symposium on Risk and Safety of Complex Structures and Components (IRAS 2019), Procedia Struct Integrity., 22, pp. 259-266.

DOI: $10.1016 /$ j.prostr.2020.01.033.

[21] Liu, Y. and Weyers, R.E. (1998). Modeling the time to corrosion cracking in chloride contaminated reinforced concrete structures, ACI. Mater. J., 95(6), pp. 675-680.

[22] Davidovici, V. and Haddadi, A. (1982). Calcul pratique de réservoirs en zone sismique, Annales de l'ITBTP, Paris., (409).

[23] Fascicule 74 texte officiel. (1998). Construction des réservoirs en béton-Cahier des clauses techniques générales. Ministère de l'équipement des transports et du logement, Paris, France.

[24] Val, D.V. and Melchers, R.E. (1997). Reliability of deteriorating RC slab bridges, J. Struct. Eng (ASCE)., 123(12), pp. 1638-1644. DOI: 10.1061/(ASCE)0733-9445(1997)123:12(1638).

[25] McGee, R.W. (2001). On the service life modelling of tasmanian concrete bridges. PhD thesis in Civil and Mechanical Engineering, University of Tasmania.

[26] Val, D.V. and Stewart, M.G. (2003). Life-cycle cost analysis of reinforced concrete structures in marine environments, J. Struct. Saf., 25, pp. 343-362. DOI: 10.1016/S0167-4730(03)00014-6.

[27] Weyers, R.E. (1993). Concrete bridge protection, repair, and rehabilitation relative to reinforcement corrosion: a methods application manual. Washington: Strategic Highway Research Program, National Academy of Sciences DC 20418.,(202), pp. 334-3774.

[28] Aoues, Y. and Bastidas Arteaga, E. (2011). Conception optimale des structures en béton soumises à la pénétration d’ions de chlorures. 29éme Rencontres Universitaires de Génie Civil, Tlemcen, 187-195.

[29] BAEL 91 modifiées 99. (2000). Règles techniques de conception et de calcul des ouvrages et constructions en béton armé suivant la méthode des états limites. Fascicule 62, France, DTU P 18-702.

[30] Hobbs, D.W. (1999). Aggregate influence on chloride ion diffusion into concrete, J. Cement Concrete. Res.,29, pp. 1995-1998. DOI: 10.1016/S0008-8846(99)00188-X.

[31] Baroghel Bouny, V. (2005). Nouvelle approche performentielle et prédictive fondée sur les indicateurs de durabilité. Laboratoire Central des ponts et chaussées, Paris, France.,4.

[32] Norme Française Homologuée. (2002). Béton-Partie 1: Spécification, performances, production et conformité. France: NF EN., 206-1.

[33] Nguyen, P.T. (2014). Étude multiphysique du transfert de chlorures dans les bétons insaturés : Prédiction de l'initiation de la corrosion des aciers. Thèse de doctorat en Génie Civil, Université de la Rochelle, France.

[34] Blankwoll, A. (1997). History of the gimsoystaumen bridge repair project. International conference-repair of concrete structures, From theory to practice in a marine environment, Norvége, 53. 